\title{
Political Competition between Differentiated Candidates
}

\author{
STEFAN KRASA \\ MATTIAS POLBORN
}

CESIFO WORKING PAPER No. 2560

CATEgory 2: Public ChOICE

FEBRUARY 2009
An electronic version of the paper may be downloaded
- from the SSRN website: Www.SSRN.com
- from the RePEc website: $\quad$ www.RePEc.org
- from the CESifo website: www.CESifo-group.org/wp




\title{
Political Competition between Differentiated Candidates
}

\begin{abstract}
We introduce a framework of electoral competition in which voters have general preferences over candidates' characteristics and policies. Candidates' immutable characteristics (such as gender, race or previously committed policy positions) are exogenously differentiated, while candidates can choose any policy for the remaining issues to maximize their winning probability. Voters have general preferences over the vectors of candidate characteristics and policies, and vote sincerely. Candidates are uncertain about the distribution of voter preferences. We characterize a condition on voter preferences (satisfied in most existing models) under which candidates' equilibrium policies generically converge. In contrast, for voter preferences that violate this condition, we construct a class of models in which policy divergence arises in the unique and strict Nash equilibrium. As a normative criterion, we define competition-efficiency and provide conditions under which the equilibrium is or is not competition-efficient.
\end{abstract}

JEL Code: D72, D60.

Keywords: multidimensional policy, voting, issue ownership, normative analysis of political competition.

\author{
Stefan Krasa \\ Department of Economics \\ University of Illinois \\ 1206 South 6th Street \\ Champaign, IL 61820 \\ USA \\ skrasa@uiuc.edu
}

\author{
Mattias Polborn \\ Department of Economics \\ University of Illinois \\ 1206 South 6th Street \\ Champaign, IL 61820 \\ USA \\ polborn@uiuc.edu
}

January 25, 2009

We would like to thank seminar audiences in Berkeley, Clemson, and Harvard-MIT, in particular Ernesto Dal Bo, Matthias Messner, Maggie Penn, Ken Shepsle and Jim Snyder for helpful comments. 


\section{Introduction}

There are two fundamentally different approaches in models of platform choice by political candidates. In the Downsian tradition, candidates can commit to a policy, and may be motivated either by the desire to win the election, or by the policy that is implemented after the election. In the citizen-candidate model, candidates are policy-motivated and unable to commit to any platform other than their preferred choice. In this paper, we introduce a multidimensional policy model that combines features of both approaches. Candidates are fixed on some positions, which are interpreted either as unchangeable characteristics of the candidate (like a candidate's previous experience, gender or race), or as those issues for which candidates strongly prefer a particular policy so that promises of implementing a different policy are not credible. On other issues, candidates are more flexible, and they are willing to use the positions on these issues as tools to get elected.

The idea that candidates differ in some fixed issues while they are flexible on others has been introduced in the political science literature by Erikson and Romero (1990) and Adams and Merrill (2003), who analyze whether candidates select the same policy position. While the equilibrium in Erikson and Romero (1990) features policy convergence (i.e., candidates choose the same policies), candidates diverge in the model of Adams and Merrill (2003). The first major contribution of our paper is to specify a general model that allows us to understand how the type of voter preferences generates convergence or divergence results, and allows us to analyze how differences in fixed positions or characteristics affect the candidates' platform choice.

In our model, candidates are exogenously differentiated with respect to immutable "characteristics". Candidates choose "policy" positions with the objective to maximize their respective winning probability. Voter preferences over the candidates' vectors of characteristics and policies are very general (for example, not necessarily assumed to be separable across issues), and the distribution of voter preferences depends on a state variable $\omega$ that is unknown to candidates at the time they choose their positions.

We identify a general property of voter preferences, called uniform candidate ranking (UCR). When voters have UCR preferences, office-motivated candidates generically choose identical policies in any pure strategy equilibrium (even in a multidimensional setting), i.e., there is policy convergence. All standard models in the literature - such as the one-dimensional Downsian model, the Downsian model with uncertainty about the median, the Downsian model with valence, or the probabilistic voting model - use voters with UCR preferences, ${ }^{1}$ and thus provide an electoral incentive to convergence; therefore, to obtain policy divergence in this class of models, additional factors and incentives must be build into this class of models.

While the existing standard models have UCR voters, there are natural settings in which voters have non-UCR preferences. A second main contribution of this paper is to introduce and explore a new

\footnotetext{
${ }^{1}$ An exception is the model by Adams and Merrill (2003), which we discuss in more detail in Example 3 below.
} 
and appealing class of such models. In particular, we consider a "differential skills" model in which citizens have diverse preferences defined over the quantities of different public goods provided by the government, and the office-holder's identity influences the production of public goods: Each candidate has one public good in whose production he is "better" than his opponent, in the sense that he can produce more output from the same amount of expenditure. In this setup, we show the existence of a unique strict Nash equilibrium in which candidates choose different proposals (i.e., spending allocations). When public goods are well-substitutable against each other, then candidates emphasize that issue in which they already have an exogenous advantage. In contrast, when the two public goods are poor substitutes, then candidates attempt to partially compensate by allocating more money to their weak spot. Compensating for deficiencies is never complete, though. The candidate who is exogenously stronger in the production of good $i$ always produces more of good $i$ in equilibrium than his competitor, and is supported by those voters for whom the supply of good $i$ is relatively important.

The equilibrium of the differential skills model also contrasts sharply with the equilibrium in a standard one-dimensional model with uncertainty about the median's position. In that model, both candidates converge to the "median median". ${ }^{2}$ For example, a shift in the likely position of the median voter to the left would mean that candidates of both parties choose more liberal positions than previously, but a voter preference shift would not translate into a "good year" for Democrats in the sense, say, that they win substantially more seats in Congress. In contrast, candidates in our differential skills model "stick to their guns" (i.e., do not change their platform in the face of shifting voter preferences), and changes in the likely distribution of the median translate into changes in winning probability. They do this not because they are convinced that their position is "right for the country"; after all, they are by assumption purely office-motivated. Rather, they know that adjusting their platform in the direction of their opponent is not going to help them electorally in states of the world where a majority of voters puts a larger emphasis on their opponent's strong issues. Considering the behavior of candidates in many political campaigns, the rigidity result of the differential skills model is a natural and appealing feature. Furthermore, the model captures the idea of "issue ownership" by candidates who are endowed with advantages and disadvantages in different policy fields. The (mostly informal) political science literature on issue ownership, starting with the seminal paper by Petrocik (1996), argues that the weak candidate in a particular policy area cannot benefit by simply copying the platform of the strong candidate in this area so that candidates remain differentiated; each candidate has strong and weak areas (from the perspective of all voters), but those voters who care primarily about a candidate's strong area are likely to support him.

While our policy space is multidimensional (since our most interesting results require at least one fixed characteristic and one flexible policy issue), the model is nevertheless very tractable. For example, in the differential skills model, we use a one-dimensional type space of voters for which it is easy to characterize existence and properties of pure strategy equilibria. The same is true if the number of

\footnotetext{
${ }^{2}$ In this model, the state of the world affects the position of the median voter. The "median median" is the position of the median voter in the median state of the world.
} 
policy issues is small and the positions that candidates can take on each issue are sufficiently discrete (e.g., binary in the sense that a candidate can be either for or against a particular proposal). Also note that the probabilistic voting model, which is a special case of our model, also often has a pure strategy equilibrium.

Finally, we focus on the welfare aspects of the equilibrium in our model. There is a general intuitive notion that policy convergence such as the one arising in the one-dimensional standard model is excessive over-convergence, effectively depriving voters of a real choice. Myerson (1993) describes this argument, as well as its flaws, as follows:

"Many authors seem to accept Hotelling's view that convergence of candidates is an undesirable outcome, because this 'excessive sameness' gives voters no real choice. This view ignores some crucial differences between the economic and political interpretations of Hotelling's game. In the economic interpretation, when two shops are locating on Main Street, minimization of the consumers' total transportation cost requires separation of the two shops. In the political interpretation, however, every voter's utility is derived from the policy position of the winning candidate (rather than the policy position of the one for whom he votes), and so voters get no intrinsic utility from a diversity of options in the selection. Thus, candidate convergence in equilibrium does not necessarily cause any welfare loss."

Uncertainty over the preferences of voters affects this argument substantially. We say that the equilibrium is competition-inefficient if a social planner could change the equilibrium platform of the candidates in a way that makes a majority of voters better off. ${ }^{3}$ Equilibria in which both candidates have the same fixed characteristics and choose the same policy positions are, generically, competition-inefficient: A social planner would like to give the voters more choice than the candidates choose to give them in equilibrium. However, when candidates have different characteristics, and only voters' preferences on fixed positions are uncertain, then the equilibrium is competition-efficient.

We present the model in the next section. In Section 3, we define and characterize preferences that allow for a uniform ranking of candidates. The main convergence and divergence results are in Section 4. In Section 5, we define and analyze competition-efficiency of the equilibrium. We discuss the relation to previous literature in Section 6. Section 7 concludes. All proofs are in the Appendix.

\section{The Model}

Two candidates, $j=0,1$, compete in an election. Candidates are office-motivated: They receive utility 1 if elected, and utility 0 otherwise, independent of the implemented policy. Candidate $j$ has fixed

\footnotetext{
${ }^{3}$ Technically, we ask whether, given equilibrium platforms $\left(a^{0}, a^{1}\right)$, there exists another pair of platforms $\left(\hat{a}^{0}, \hat{a}^{1}\right)$ such that it is more likely that a majority prefers the outcome under $\left(\hat{a}^{0}, \hat{a}^{1}\right)$ to the equilibrium outcome, than the other way around.
} 
characteristics $c^{j} \in C$, which we also call his type. If elected, Candidate $j$ implements a policy described by $a^{j}=\left(a_{i}^{j}\right)_{i=1, \ldots, I}$. Candidate $j$ 's policy position is $a^{i} \in A$. Except for section 4.2 we assume for simplicity of exposition that $A$ is finite.

Uncertainty in the model is described by a probability space $(\Omega, D, \mu)$. Let $P_{r}$ be the set of preferences on $C \times A$. Then the preferences of voter $\ell \in \mathfrak{I}=\{1, \ldots, L\}$ in state $\omega \in \Omega$ are $\geq_{\omega}^{\ell} \in P_{r}$. More formally, voter $\ell$ 's random preferences are given by a measurable function ${ }^{4} t_{\ell}: \Omega \rightarrow P_{r}{ }^{5}$

If a voter has a strict preference, then it is a weakly dominant strategy to vote for the preferred candidate. If a voter agent is indifferent, he could in principle vote for any candidate or abstain. We assume that he abstains, which is quite natural (e.g., in the presence of even very small voting costs), and also allows us to easily model a random number of voters $L(\omega) \leq L$ by simply by modeling $L-L(\omega)$ voters as indifferent between all policies, so that they will abstain no matter what policies the candidates choose.

The timing of the game is as follows:

Stage 1 Candidates $j=0,1$ simultaneously announce policies $a^{j} \in A$. A mixed strategy by agent $j$ consists of a probability distribution $\sigma^{j}$ over $A$.

Stage 2 Each citizen votes for his preferred candidate, or abstains when he is indifferent.

Candidate $j$ wins the election if he receives more votes than his opponent. In case of a tie between the candidates, each wins with probability $1 / 2$. Let $W^{j}\left(\omega, a^{0}, a^{1}\right)$ denote Candidate $j$ 's winning probability in state $\omega$, given policies $a^{0}$ and $a^{1}$. Formally, $W^{0}\left(\omega, a^{0}, a^{1}\right)=\xi\left(v\left(\omega, a^{0}, a^{1}\right)\right)$, where $\xi(x<0)=0$, $\xi(0)=1 / 2$ and $\xi(x>0)=1$; and $v\left(\omega, a^{0}, a^{1}\right)=\#\left\{\ell \mid\left(c^{0}, a^{0}\right) \geq_{\omega}^{\ell}\left(c^{1}, a^{1}\right)\right\}-\#\left\{\ell \mid\left(c^{1}, a^{1}\right) \geq_{\omega}^{\ell}\left(c^{0}, a^{0}\right)\right\}$.

Clearly, $W^{j}$ also depends on the random preference profile $t$, i.e., the winning probabilities change when we change the preference profile from $t$ to $t^{\prime}$, which we will do when we explore genericity. When necessary, we indicate the dependence of $W^{j}$ on the preference profile $t$ or $t^{\prime}$ by writing $W_{t}^{j}$ or $W_{t^{\prime}}^{j}$ instead of $W^{j}$.

\subsection{Interpretation}

Key ingredients of our model are the following: (i) Candidates are differentiated through some fixed characteristics, but can choose among several possible policy positions on other issues; (ii) multidimen-

\footnotetext{
${ }^{4}$ Since $P_{r}$ is finite, measurability means that the set of all states $\omega$ that is mapped into one particular preference is measurable.

${ }^{5}$ In order to analyze which properties of equilibrium are "generic", we will need to "slightly perturb" the distribution of voter preferences (in order to see whether the properties of equilibrium survive such a small perturbation). We cannot do this directly by slightly perturbing the distribution of $\omega$, because two states that are very close to each other may translate into very different preference distributions (i.e., preferences are not "continuous" in $\omega$ in any meaningful sense). Therefore, we keep the distribution of $\omega$ always the same, but rather consider different preference profile mappings $t^{\prime}$ that are close to $t$ in the sense that $t$ and $t^{\prime}$ only differ with "small" probability.
} 
sionality and general voter preferences over policy vectors; and (iii) candidates are "office-motivated". We now discuss these assumptions.

Fixed characteristics. We assume that candidates have fixed characteristics, which can either be interpreted as fixed attributes that may be relevant for voters, such as gender, race, professional experience, belonging to a "political dynasty" (c.f., Dal Bo, Dal Bo, and Snyder (2006)), or as previously committed policy positions (e.g., a candidate who has been pro-choice throughout his career may find it hard to credibly switch to a pro-life position).

The assumption that candidates are differentiated in some fixed characteristics is, of course, already present in several other papers, for example, Erikson and Romero (1990). However, to our knowledge, no other paper (except our earlier paper Krasa and Polborn (2007)) analyzes the effects of fixed characteristics when candidates can choose policies on (possibly multiple) flexible issues.

Policy space $\boldsymbol{A}$. While, in our model, $A$ can generally be any arbitrary set, we often consider more structured sets in applications. An important example of a policy space is $A=\prod_{i=1}^{I} A_{i}$, where $I$ is the number of distinct policy issues, and $A_{i}$ is the set of possible positions on issue $i$. For example, $A_{i}=\{0,1\}$ if a position on issue $i$ is either to be for or against implementing a particular program. In another application, analyzed in Section 4.2, we focus on a setting in which candidates choose proposals on how to allocate the government's budget between two public goods. Policy $a \in A=[0,1]$ corresponds to the fraction of the budget allocated to the production of first public good, with the remainder going to the second public good.

Note that preferences are defined on $C \times A$ and are always multidimensional (even if $A=[0,1]$ ). Rather than assuming separability of $C$ and $A$, we allow for arbitrary preferences and investigate what properties of preferences result in policy convergence or divergence.

Candidate motivation. We assume that candidates are "office-motivated", i.e., choose their policy positions in order to maximize their winning probability. In a one-dimensional world, policy-motivation and office-motivation are diametrically opposed, because the flexible policy dimension is the only policy, and consequently the only one about which candidates could care. Assuming that candidates are only motivated by the perks of office and would choose literally any policy to get elected is probably too cynical in a one-dimensional world.

In contrast, when there are multiple issues, policy-motivation may lead to very similar choice behavior as pure office-motivation. One can think of (some) fixed characteristics as those issues on which the candidate has strong convictions and where he cannot credibly (or does not want to) commit to another position. On some other issues, the candidate, in principle, also has a preferred position, but his preference is not that strong; he is willing to compromise on these "flexible" issues in order to get elected 
and then be able to implement his preferred policy on those issues that are more important to him. A candidate who is policy-motivated in the way described (i.e., mostly cares about his "fixed positions") would choose his flexible positions (almost) as if he was purely office-motivated. ${ }^{6}$

\section{Uniform Candidate Ranking Preferences}

Some results of our model hold for very general voter preferences, while others hold only on a (large) subset of all possible voter preferences. Before starting to analyze the equilibrium, it is therefore useful to introduce a key property of preferences that determines whether or not policy convergence occurs.

Suppose that both candidates choose the same policy $a \in A$. We say that a voter has uniform candidate ranking $(U C R)$ preferences if a voter's preferences for the candidates is independent of $a$. For example, suppose that $C=A=\{0,1\}$. Preferences are therefore defined on $\{0,1\} \times\{0,1\}$, where the first coordinate is the candidate's fixed characteristic and the second one the policy issue. A UCR voter prefers $(0,0)$ to $(1,0)$ if and only if he also prefers $(0,1)$ to $(1,1)$.

Definition 1 (Rankability of candidates, UCR) Preferences $\geq_{\omega}$ on $C \times A$ allow for a uniform candidate ranking if, in any state $\omega$, the following holds:

$$
\left(c^{0}, a\right) \geq_{\omega}\left(c^{1}, a\right) \text { if and only if }\left(c^{0}, a^{\prime}\right) \geq_{\omega}\left(c^{1}, a^{\prime}\right),
$$

for all $c^{0}, c^{1} \in C$ and all $a, a^{\prime} \in A$.

Models in which candidates have no fixed characteristics (e.g., the standard one-dimensional Downsian model) automatically satisfy Definition 1. Also, a model with a one-dimensional policy space and random candidate valences satisfies UCR, as does a model with uncertainty about the preferred position of the median voter (as well as valence). Likewise, voter preferences in the probabilistic voting model (see, e.g., Lindbeck and Weibull (1987), Lindbeck and Weibull (1993), Coughlin (1992)) satisfy UCR.

For example, consider a model with stochastic valence: In state $\omega=\left(\omega^{0}, \omega^{1}\right)$, voter $\theta$ 's utility from Candidate 0 is given by $\omega^{0}-\left(a^{0}-\theta\right)^{2}$, while his utility from Candidate 1 is given by $\omega^{1}-\left(a^{1}-\theta\right)^{2}$. Clearly, when $a^{0}=a^{1}$, the voter strictly prefers Candidate 0 if and only if $\omega^{0}>\omega^{1}$. Since this preference is independent of the particular policy $a^{0}=a^{1}$, UCR is satisfied.

We discuss below in which circumstances it is reasonable to suppose that voters have UCR preferences, but start by classifying the set of utility functions that represent such preferences.

Theorem 1 The following statements are equivalent:

\footnotetext{
${ }^{6}$ Of course, this argument only applies if $c^{0} \neq c^{1}$ (which, we would argue, is not a particularly strong assumption to make in most elections). If, instead, candidates agree on all fixed characteristics, then office-motivation and policy-motivation (on the remaining, flexible, issues) would generally lead to different behavior.
} 


\section{Rational (i.e., complete and transitive) preferences $\geq_{\omega}$ on $C \times A$ satisfy UCR.}

2. The preferences $\geq_{\omega}$ can be described by a utility function $u(c, a, \omega)=g(f(c), a, \omega)$ where $f: C \rightarrow$ $Y \subset \mathbb{R}$, and $g: Y \times A \rightarrow \mathbb{R}$ is strictly monotone in $y \in Y$.

Suppose that $A=\prod_{i=1}^{I} A_{i}$ and that If the utility function is additively separable across $A$ and $C$, i.e., $u(c, a)=u_{C}(c)+u_{A}(a)$ then Theorem 1 immediately implies that preferences satisfy UCR. Suppose, for example, that $C \subset \mathbb{R}$ and that $A=\prod_{i=1}^{I} A_{i}$ (i.e., there are $I$ different issues). Then the "weighted issue preferences" of Krasa and Polborn (2007), can be represented by a utility function of this form, i.e.,

$$
u(a, \omega)=\lambda_{C, \omega}\left|c-\theta_{C, \omega}\right|+\sum_{i=1}^{I} \lambda_{i, \omega}\left|a_{i}-\theta_{i, \omega}\right| .
$$

Parameters $\theta$ and $\lambda$ can be interpreted as ideal positions and weights that measure the relative importance of the fixed and selectable issue, respectively. ${ }^{7}$ Another class of preferences with additively separable utility function are those where indifference curves are circles around the ideal points on each issue and the fixed characteristic. However, preferences that allow for uniform ranking of candidates do not have to have a utility representation that is of the form $u_{C}(c)+u_{A}(a)$. To see this, consider the following example.

Example 1 Let $c^{0}=0, c^{1}=1$, and assume that there is only one binary policy issue, i.e., $A=\{0,1\}$. The voter's preference is $(0,0)>(0,1)>(1,1)>(1,0)$. Clearly, the preferences satisfy UCR, as Candidate 0 is always preferred to Candidate 1 . However, these preferences cannot be represented by an additively separable utility function. In particular, $(0,0)>(0,1)$ would imply $u(0)>u(1)$. However, $(1,1)>(1,0)$ implies $u(1)>u(0)$, a contradiction.

In contrast, preferences may violate Definition 1 if a candidate's characteristics influence his competence in implementing different policies. For example, suppose that the fixed characteristic is whether or not a candidate has served in the military, while the policy issue is whether or not to go to war with some other country. Suppose that a voter thinks that the candidate who has served in the military is a better leader for the country during a war, while his opponent with a civilian background is preferable for the voter in peacetime. Formally, such a voter could have the preference $(1,1)>(0,0)>(1,0)>(0,1)$, that is, prefers most to go to war with a leader with military experience, while the second best option is not to go to war and have a leader with civilian background, which again is better than both "mixed" policy vectors. These preferences violate UCR, because the voter's preferred candidate changes from the situation that both propose to go to war to another one in which both propose peace.

\footnotetext{
${ }^{7}$ Implicitly, separability of preferences is assumed in several internet-based political comparison programs. For example, smartvote.ch (a cooperation project of several Swiss universities) collects the political positions of candidates in national elections by asking candidates a number of yes/no questions on different political issues. Voters can answer the same questions on a website (and also choose a weight for each issue) and are given a list of those candidates who agree with them most. Similar programs exist for the U.S. (http://www.myspace.com/mydebates), Germany (http://www.wahl-o-mat.de), Austria (http://www.wahlkabine.at/) and the Netherlands (http://www.stemwijzer.nl/).
} 
While additively separable preferences imply that a voter's preferred policy on any issue is independent of the identity of the elected candidate, Definition 1 allows, more generally, for preferences where the ranking of policies on a given issue depends on the identity of the politician; however, if both candidates propose the same policy, then the identity of a voter's preferred candidate should not depend on which particular policy both candidates propose. Essentially, differences between candidates' fixed characteristics are sufficiently important for voters to trump considerations of different ability to implement different policies.

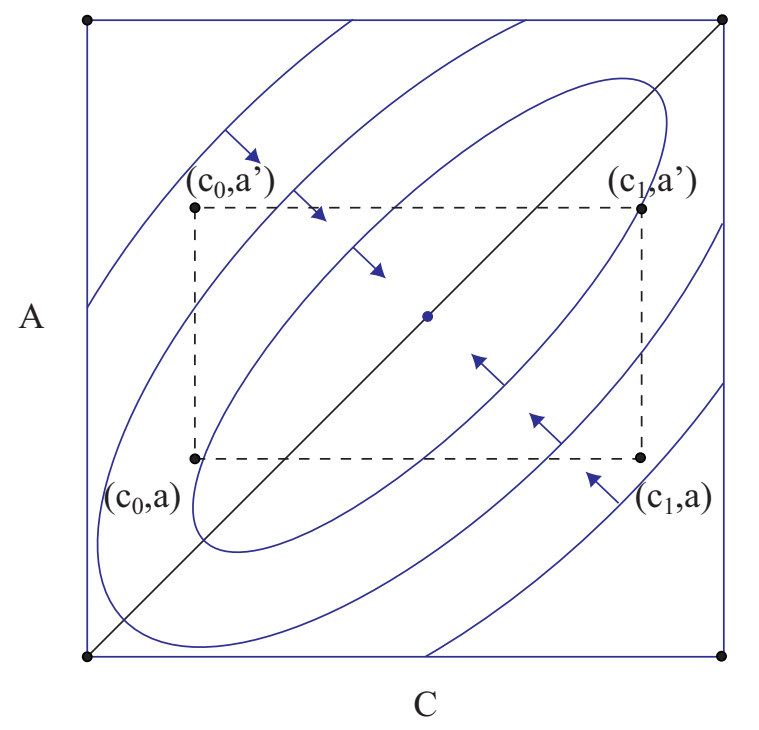

Figure 1: Preferences where candidates cannot be ranked uniformly

Figure 3 provides a geometric representation of non-UCR preferences. Candidates 0 and 1 have fixed characteristics $c_{0}$ and $c_{1}$, which are measured on the horizontal axis. The policy issue is measured on the vertical axis, and the voter's indifference curves are given by ellipses. Since $\left(c_{0}, a\right)>\left(c_{1}, a\right)$, the voter prefers Candidate 0 if both candidates choose policy $a$. In contrast, $\left(c_{1}, a^{\prime}\right)>\left(c_{0}, a^{\prime}\right)$, i.e., if both candidates choose policy $a^{\prime}$, then the preference is reversed.

\section{Convergence and Divergence of Equilibrium Policies}

In this section, we characterize the equilibrium in the platform choice game between the two candidates. We are particularly interested in "policy convergence", i.e., whether or not the two candidates propose the same policies. This issue is a long-running theme in the analysis of spatial models of voting. In the classical model of Downs (1957), candidates converge on the preferred position of the median voter. 
Since then, many models have been constructed with the objective of developing a better understanding for why politicians, in reality, often choose to differentiate from their opponent.

A meaningful notion of policy convergence requires that there is a pure strategy equilibrium of the game between candidates in which they choose the same policies. In contrast, divergence can take different forms. First, candidates may both strongly prefer to choose a different position than their opponent (so there is divergence in a strict Nash equilibrium); we refer to this as strong divergence. For example, in the model of Calvert (1985), the location of the median voter is uncertain and candidates are (also) policy-motivated with ideal points on different sides of the expected position of the median voter. In equilibrium, candidates choose different positions, and strictly prefer the position where they locate, respectively, to any other position, and in particular, to locating at the position of the other candidate. Second, in any mixed strategy equilibrium, candidates choose different policies with positive probability, but without having a strict preference for their position; we refer to this as weak divergence.

In a model without time structure like ours (i.e., where there is only one point in time at which candidates choose their positions), strong and weak divergence are observationally similar: Candidates choose different positions. However, consider how the two types of divergence would play out in a more realistic model in which candidates can choose positions during several periods of campaigning, and in which there is, ceteris paribus, some small advantage to committing early (say, that makes it cheaper for candidates to "get the message out" rather than waiting till the last moment before the election before announcing the platform).

Suppose first that the static game has an equilibrium with strong divergence. Then, in a dynamic version, candidates can choose their positions at the beginning of the campaign and would never be tempted to revise those; they also have no incentive to wait for the other candidate to move first. In contrast, suppose now that there is only a mixed strategy equilibrium in the static, constant-sum game. In a dynamic version of the game in the same setup, candidates would not commit to a platform early, but rather, they would wait until the very last period and then simultaneously reveal their respective platforms. Alternatively, if candidates can adjust their platform throughout the campaign, we should see them changing positions repeatedly throughout the campaign, as at every moment, at least one of the candidates has another platform that would increase his winning probability. In summary, strong divergence appears to be the more robust form of divergence, and the one that we believe corresponds more to divergence that we observe in reality.

While it is obviously impossible to guarantee existence of a pure strategy equilibrium in our general framework with arbitrary preferences, there are sufficiently large classes of voting games in which pure strategy equilibria exist and are robust to small changes of the distribution of voters. For example, the probabilistic voting model, the multidimensional policy model with deterministic valence of Ansolabehere and Snyder (2000), or the binary policy model of Krasa and Polborn (2007) are special cases of our general framework in which pure strategy equilibria are known to exist. Also, in section 4.2 we 
provide an existence result for pure strategy equilibria in the differential skills model.

\subsection{Convergence Results}

We now characterize the equilibrium of our model. Our first result shows that, if candidates' fixed characteristics coincide, then there is either policy convergence, or weak policy divergence.

Theorem 2 Suppose that $c^{0}=c^{1}$.

1. If there exists a pure strategy Nash equilibrium $\left(a^{0}, a^{1}\right)$ with $a^{0} \neq a^{1}$, then $\left(a^{0}, a^{0}\right)$ and $\left(a^{1}, a^{1}\right)$ are also pure strategy Nash equilibria.

2. If there exists a strict Nash equilibrium $\left(a^{0}, a^{1}\right)$ then $a^{0}=a^{1}$ and this strict Nash equilibrium is the unique Nash equilibrium (pure or mixed).

Theorem 2 shows that, as long as candidates' fixed characteristics do not differ, pure strategy equilibria with policy divergence cannot be unique: Whenever they exist, there is also an equilibrium with policy convergence; moreover, any policy divergence is weak in the sense that candidates do not strictly prefer the particular platform they choose. Thus, our result generalizes the convergence results familiar from the standard Downsian model to a setup in which policies are multidimensional and there is uncertainty about preferences. In the Downsian model under certainty both candidates choose the policy that is most preferred by the median voter. If the position of the median voter is uncertain, then candidates converge on the "median median," that is, there is no other position that would make a majority better off in a majority of states. While there is no geometric notion of a median voter in multiple dimensions, the intuition of the median voter theorem generalizes. That is, in an equilibrium, no other position can make a majority of voters better off in a majority of states. The reason is that, if such a policy position existed, then either candidate could deviate to it, thereby increasing his winning probability.

The following Theorem 3 also considers the topic of convergence, but in contrast to Theorem 2, it allows for candidates' fixed positions to differ and focuses on the case that all voters have UCR preferences. Under these conditions, there is policy convergence in all strict Nash equilibria. Moreover, if there is a strict Nash equilibrium, then it is unique.

Theorem 3 Suppose that all voters have UCR preferences (in contrast to Theorem $2 c^{0}$ and $c^{1}$ are arbitrary).

1. There is policy convergence in any strict Nash equilibrium $\left(a^{0}, a^{1}\right)$, i.e. $a^{0}=a^{1}$.

2. If there exists a strict Nash equilibrium then it is the unique Nash equilibrium (pure or mixed). 
The intuition for the Theorem is as follows. Suppose both candidates choose the same policy $a$. Since voters have UCR preferences, the winning probabilities do not change if both candidates switch to $a^{\prime}$. This means that the entries on the diagonal of the payoff matrix (i.e., where $a^{0}=a^{1}$ ) are identical. One can then show that strict Nash equilibria can never be off the diagonal, and hence policy convergences arises.

Theorem 3 shows that the policy convergence result of the classical Downsian model is robust in our more general setting with uncertainty and different fixed candidate characteristics, as long as voters have UCR preferences. We will show below that this changes if voters have non-UCR preferences.

If there is no strict equilibrium, then equilibria may not be unique and may involve divergence. Consider the following example.

Example 2 There is one policy issue with two positions $\{0,1\}$, and no fixed characteristics. Let $\left\{\Omega_{0}, \Omega_{1}\right\}$ be a partition of $\Omega$ with $P\left(\Omega_{0}\right)=P\left(\Omega_{1}\right)=0.5$ such that all voters prefer position $i$ for all $\omega \in \Omega_{i}$. Then $(0,1)$ is an equilibrium with divergence. (As Theorem 2 shows, $(0,0)$ and $(1,1)$ are equilibria as well.)

While there is divergence in one equilibrium of Example 2, this result appears particularly fragile in that it depends crucially on both states being exactly equally likely. Once one state becomes a little more likely than the other state, the equilibrium with divergence disappears, and the Nash equilibrium will be unique and strict. We are therefore particularly interested in results that hold "generically". That is, we want to discard properties that hold only in an equilibrium that exists for a very particular distribution of voter preference profiles, but ceases to exist for small perturbations of the original distribution.

To define our notion of genericity formally, we need to introduce some notation. Let $P_{r}$ be the set of all rational preferences for any of the $L$ voters. Then $t_{i}: \Omega \rightarrow P_{r}$ maps the state of the world to voter $i$ 's preferences. The set of all such possible mappings for any voter is denoted by $T_{r}=\left\{t \mid t: \Omega \rightarrow P_{r}\right\}$. Sometimes, we need to restrict the class of possible voter preferences to $P \subseteq P_{r}$ (e.g., $P$ could be the set of UCR preferences). In this case, let $T$ denote the analogue of $T_{r}$, i.e. $T=\{t \mid t: \Omega \rightarrow P\}$ is the set of random preferences chosen from $P \subseteq P_{r}$.

Let $d_{P}$ be a metric on $P$. Since $P$ is finite, any metric will generate $\mathfrak{P}$ (the set of all subsets of $P^{L}$ ) as the $\sigma$-algebra of Borel sets. We now define a metric $d_{T}$ on $T$ in the standard way, i.e., $d_{T}\left(t, t^{\prime}\right)=$ $\int d_{P}\left(t(\omega), t^{\prime}(\omega)\right) d \mu(\omega){ }^{8}$

A preference profile is given by $t=\left(t_{1}, \ldots, t_{L}\right) \in T^{L}$. We extend the metric to $T^{L}$ in the standard way, i.e., let $t=\left(t_{1}, \ldots, t_{L}\right) \in T^{L}$ and $t^{\prime}=\left(t_{1}^{\prime}, \ldots, t_{L}^{\prime}\right) \in T^{L}$ be two random preference profiles then $d_{T^{L}}\left(t, t^{\prime}\right)=\max _{i=1, \ldots, L} d_{T}\left(t_{i}, t_{i}^{\prime}\right)$.

\footnotetext{
${ }^{8}$ In order to ensure that $d_{T}\left(t, t^{\prime}\right)=0$ implies $t=t^{\prime}$ we use the standard approach of replacing $t$ by the equivalence class of all functions $t$ with $t=t^{\prime}$ a.e.
} 
Definition 2 A property $E$ of the equilibrium is said to hold generically for preferences in $T^{L}$ if and only if $E$ holds for an open and dense subset of $T^{L}$.

To understand the above topology, note that two mappings $t$ and $t$ ' are "close" if they differ from each other only on a set $B$ of states of the world that has small probability $\mu(B)$. If $\mu(B)$ goes to zero, then $t$ and $t^{\prime}$ generate the same preference profiles for almost all states of the world.

For an equilibrium property to hold "generically", Definition 2 requires that it holds for "almost all" $t$ : Specifically, if the property is satisfied for $t$, then there exists $\varepsilon>0$ such that it is also satisfied for all $t^{\prime}$ such that $d_{T}\left(t, t^{\prime}\right)<\varepsilon$. Moreover, the set of preferences for which the property holds is dense: If the property is violated for a particular $t$, then there exists an arbitrarily close $t^{\prime}$ for which the property holds.

We now show that, for generic preference profiles, any pure strategy equilibrium is strict. (Of course, in view of example 2 , this result does not hold for all preference profiles).

Theorem 4 Let $T$ be the space of random UCR preferences. Then, generically, there exists either a strict Nash equilibrium or a mixed strategy equilibrium.

Combining Theorems 3 and 4 shows that policy convergence holds generically for any pure strategy Nash equilibrium, as long as voters have UCR preferences. Thus, the convergence result of the standard Downsian model with office-motivated candidates is generically robust in our more general multidimensional framework as long as voters have UCR preferences.

To our knowledge, the only model with an equilibrium in which office-motivated candidates choose divergent platforms is Adams and Merrill (2003). Our results indicate that this must be due to non-UCR preferences in their model. Voters in their model have additively separable preferences that incorporate both a (continuous) policy issue and partisan preferences (akin to "fixed characteristics" in our terminology). Specifically, consider the following example.

Example 3 There is one fixed characteristic, which Adams and Merrill (2003) refer to as partisanship, and a one-dimensional policy variable in $[0,1]$. A citizen's type is of the form $(P, \theta)$, where $P \in\{D, R\}$ denotes the partisan preference, and $\theta$ the most preferred policy. Utility of type $(D, \theta)$ from Candidate $(D, x)$ is $B-|\theta-x|$ and $-|\theta-x|$ from Candidate $(R, x)$. Similarly, type $(R, \theta)$ also has $\theta$ as ideal point, but gets a utility benefit of $B$ from the Republican candidate. However, this "utility function" is not a standard utility function in the sense that it completely describes behavior. In particular, they assume that citizens abstain (i) if the utility difference between candidates is below a threshold ("abstention from indifference"), or (ii) if the utility from the preferred candidate is below some threshold $T$ ("abstention from alienation"). While the model of Erikson and Romero (1990) has only the first effect and generates equilibrium convergence, the second effect may lead to (effective) preferences violating UCR. To see this, consider only the second effect, and define effective voter preferences of a Democratic partisan 
$(D, \theta)$ given policy platforms $x_{D}$ and $x_{R}$ as

$$
\begin{aligned}
& D>R \quad \Longleftrightarrow B-\left|x_{D}-\theta\right|>-\left|x_{R}-\theta\right| \text { and } B-\left|x_{D}-\theta\right|>T \\
& R>D \quad \Longleftrightarrow B-\left|x_{D}-\theta\right|<-\left|x_{R}-\theta\right| \text { and }-\left|x_{R}-\theta\right|>T \\
& D \sim R \quad \Longleftrightarrow B-\left|x_{D}-\theta\right| \leq T \text { and }-\left|x_{R}-\theta\right| \leq T
\end{aligned}
$$

In order to have some participation, $B \geq T$ and in order for the alienation constraint to matter $B \leq T+0.5$. To see that these preferences violate UCR, consider a $\theta=0$ Democratic partisan. If both candidates were to propose the same policy $x_{D}=x_{R}=0$, then $D>R$ (i.e., the voter votes for D). If, instead, $x=0.5$ then $D \sim R$, because the voter abstains from alienation. Thus, these preferences violate UCR. ${ }^{9}$

\subsection{Divergence as a result of differential skills: A model of issue ownership}

So far, we have shown that, if voters have UCR preferences, then pure strategy equilibria generically entail policy convergence. We now show that, if UCR does not hold, candidates may choose divergent platforms in a pure strategy equilibrium. ${ }^{10}$ Indeed, we provide a class of models with non-UCR preferences, in which candidates choose divergent platforms in the unique and strong pure strategy equilibrium.

A generally accepted notion in U.S. politics is that each of the two major parties has issues on which they are particularly "strong". Republican candidates are generally believed to have an advantage on national defense or, on a more local level, law enforcement, while Democrats have an advantage on issues like health care or education. Also, candidates tend to emphasize those issues on which they are strong: For example, Republican candidates often propose more spending on defense than their Democratic competitors, and vice versa for Democrats. Petrocik (1996) coins the term issue ownership for this phenomenon, and we will discuss further below how our results correspond to this theory.

Consider the following general setup. A polity provides two public goods for its citizens (e.g., schooling or law enforcement). The utility function of a voter of type $t \in[0,1]$ is $v_{t}: \mathbb{R}_{+}^{2} \rightarrow \mathbb{R}$, where $t$ parameterizes voters' preferences for good 0 versus good 1 , with low types putting more emphasis on good 0 and high types on good 1 . Formally, we assume that the marginal rate of substitution between goods 0 and 1 is decreasing in $t$,

$$
\frac{\partial}{\partial t}\left[\frac{\frac{\partial v_{t}\left(x_{0}, x_{1}\right)}{\partial x_{0}}}{\frac{\partial v_{t}\left(x_{0}, x_{1}\right)}{\partial x_{1}}}\right]<0 .
$$

\footnotetext{
${ }^{9}$ Since voters in Erikson and Romero (1990) and Adams and Merrill (2003) only fulfill transitivity for strict preferences, our theorems do not directly apply However, it is clear when comparing the two models that violation of UCR in Adams and Merrill (2003) drives the divergence result.

${ }^{10}$ Clearly, an arbitrary violation of UCR for one voter cannot be expected to result in an equilibrium with divergence. For example, the equilibrium will continue to feature convergence, if UCR is violated for some policies $a$ that would never be adopted in any equilibrium (for example, because they are strictly dominated).
} 
Standard arguments show that (3) implies that indifference curves of two different types can have at most one intersection point. As a consequence, (3) is often referred to as the "single crossing property." For example, this property holds for the CES utility functions

$$
v_{t}\left(x_{0}, x_{1}\right)=\left((1-t) x_{0}^{\rho}+t x_{1}^{\rho}\right)^{1 / \rho}
$$

which we will discuss in more detail later. The state $\omega$ defines a vector of voter types in state $\omega$. Let $t_{m}(\omega)$ denote the median of the voter types in state $\omega$.

Public goods $i=0,1$ are produced according to constant returns to scale production functions $G_{i}$ : $C \times$ $\mathbb{R}_{+} \rightarrow \mathbb{R}_{+}$. The first argument of these functions allows for candidate identity to influence production, while the second argument is interpreted as the amount of an input good used in the production. Since we assume constant returns to scale, we can assume without loss of generality that $G_{0}(c, y)=A(1-c) y$ and $G_{1}(c, y)=B c y$, where $A, B>0$ and $c \in C \subseteq[0,1]$.

Policy $a \in A$ indicates how much of the government's budget $m$ is used in the production of the first good; the remainder $m-a$ is used for the second good. Without loss of generality we can also normalize $m=1$. In this model, we will assume that $a$ is a continuous variable. The reason is that the model has sufficient additional structure to make continuity and differentiability a useful tool for the analysis. Moreover, the structure of the model allows us to prove equilibrium existence constructively even for the case of a continuous policy variable, which is not possible for the general model analyzed above. ${ }^{11}$ The following theorem characterizes the equilibrium.

Theorem 5 Suppose that utility $v_{t}(x)$ is continuous in $t$ and $x$, strictly monotone, and strictly quasiconcave in $x$, and satisfies the single crossing property (3). Assume that $0 \leq c^{0}<c^{1} \leq 1$. Let $\gamma$ be a lower bound for the elasticity of substitution for all consumption bundles $\left(x_{0}, x_{1}\right)$ and all types $t$. Suppose that

$$
\left(\frac{c^{1}\left(1-c^{0}\right)}{\left(c^{1}-c^{0}\right)^{2}}\right)^{1 / \gamma} \leq \min \left\{\frac{c^{1}}{c^{0}}, \frac{1-c^{0}}{1-c^{1}}\right\} .
$$

Then

1. There exists a pure strategy Nash equilibrium with the following properties

(a) There exists a voter type $\bar{t}$ who is indifferent between candidates 0 and 1 ; all types $t<\bar{t}$ strictly prefer Candidate 0 and all types $t>\bar{t}$ strictly prefer Candidate 1.

(b) Both candidates' equilibrium strategies maximize the utility of voter $\bar{t}$.

(c) The equilibrium strategies are independent of the distribution $\mu$ of voter types.

(d) Candidate 0 provides strictly more of public good 0 than Candidate 1, while Candidate 1 provides strictly more of public good 1 than Candidate 0.

\footnotetext{
${ }^{11}$ Of course, we could still analyze the same model with a discrete grid of feasible choices, just as in the analysis so far, and the resulting equilibrium would be very close to the one derived below, as long as the grid is sufficiently fine.
} 
2. Suppose the distribution of the median voter $t_{m}(\omega)$ in state $\omega$ has strictly positive density on $[0,1]$ then one of the following is true:

(a) The equilibrium is strict and it is the unique Nash equilibrium (pure or mixed).

(b) One of the candidate wins with probability 1 and receives $100 \%$ of the votes in almost all states $\omega \in \Omega$.

The equilibrium characterized in Theorem 5 is an equilibrium with divergence in outcomes, in the sense that Candidate 0 proposes a higher supply of good 0 than his opponent, and vice versa for Candidate 1. As we will see below, candidates also usually diverge in policy (that is, they propose a different budget allocation, $a^{0} \neq a^{1}$ ). However, there is no general relationship between competence in a policy area and budget allocation relative to the opponent: In equilibrium, candidates may choose a budget allocation that endogenously strengthens their respective strong points (i.e., $a^{0}>a^{1}$ ), or they may choose to partially compensate for their weakness (i.e., $a^{0}<a^{1}$ ). For more details on how this depends on voter preferences and, in particular, on the substitutability of the two public goods in voters' utility functions, see the next section which contains an analysis for voters with CES utility functions.

Since Candidate 0 proposes a higher supply of good 0 than his opponent, and vice versa for Candidate 1 , voters who care relatively strongly about good 0 strictly prefer and vote for Candidate 0 , and the remaining voters vote for Candidate 1. By continuity, there is one voter type $\bar{t}$ who is indifferent between the equilibrium platforms of the two candidates.

Intuitively, it is the objective of Candidate 0 to move the position of $\bar{t}$ as far as possible to the right, and vice versa for Candidate 1 . We now argue that, as a consequence, both candidates choose their equilibrium platforms to maximize the utility of voter $\bar{t}$. Suppose that Candidate 0 were to marginally deviate from this profile and rather propose a platform that maximizes the utility of voter $\bar{t}+\varepsilon$. Such a deviation implies that voter $\bar{t}$ (and some of his neighbors who voted for Candidate 0 in the equilibrium strategy profile) now strictly prefer to vote for Candidate 1 , which is bad for Candidate 0 . How about voter $\bar{t}+\varepsilon$, though? Assuming differentiability, this voter's net preference for Candidate 1 in equilibrium is of order $\varepsilon$. In contrast, a small change of Candidate 0's platform would lead only to a second order increase of the utility of voter $\bar{t}+\varepsilon$ (because the equilibrium action of Candidate 0 is already close to the action that is optimal for voter $\bar{t}+\varepsilon$ ). Thus, even a deviation by Candidate 0 to $\bar{t}+\varepsilon$ 's ideal policy (from Candidate 0 ) fails to attract the support of that voter, provided that $\varepsilon$ is sufficiently small.

As a consequence, "small" deviations from the proposed profile always diminish the set of types that support the deviating candidate. Moreover, any deviation from the proposed equilibrium profile loses the support of type $\bar{t}$ and therefore can only be attractive for a candidate if it completely "flips" the structure of voter support (i.e., if, after the deviation, high types support Candidate 0 and low types support Candidate 1; the reverse of the voter support structure in the presumed equilibrium). Condition (5) in the theorem is a sufficient condition that guarantees that such flips cannot occur. This condition 
combines voter preferences (by incorporating a bound on the rate of substitution) and technology (i.e., the difference in the productivities of the candidates). For example, preferences that are sufficiently close to perfect substitutes (i.e., if $\gamma$ is sufficiently large), (5) is always satisfied.

Voter $\bar{t}$ is determined as the voter type who is indifferent between both candidates if those candidates choose policies such as to maximize this voter's utility. Thus, the identity of this cutoff voter is determined solely by technology and preferences, but not by the distribution of voter preferences and therefore does not need to be the "median median" voter. Candidate 0 's winning probability is $\mu\left(\left\{t_{m}(\omega)<\bar{t}\right\}\right)$, while Candidate 1's winning probability is $\mu\left(\left\{t_{m}(\omega>\bar{t}\}\right)\right.$. Note that changes in the distribution of the median voter affect the candidates' respective likelihood of winning or of a tie, but not the policy they choose or the voter whom they cater to.

In contrast, in a Downsian model with uncertainty about the position of the median voter, both candidates choose the ideal point of the median of the distribution of $t_{m}(\omega)$ (i.e., the "median median"). A change in the distribution of $t_{m}(\omega)$ affects the position that candidates choose, while the winning probabilities remain unaffected.

In the equilibrium of the Downsian model with uncertainty, all citizens are indifferent between the candidates. In the differential skills model, only voter $\bar{t}$ is indifferent, while all voters with $t<\bar{t}$ strictly prefer Candidate 0 , while those with $t>\bar{t}$ strictly prefer Candidate 1 . Hence, while both the Downsian and the differential skills model predict that candidates cater to some cutoff voter, this translates into indifference among all voters only in the Downsian model, but not in the differential skills model.

In part 2 of Theorem 5, we provide conditions that guarantee uniqueness and strictness of the Nash equilibrium. Note that the condition in this part could be replaced by a weaker condition that only requires that $\mu\left(\left\{\omega \mid t_{m}(\omega) \in U\right\}\right)>0$ for any neighborhood of $U$ of $\bar{t}$. However, the disadvantage of this alternative condition is that it requires knowledge about (the endogenous) $\bar{t}$.

\subsubsection{Example: Issue ownership with CES-preferences}

To illustrate the theorem and its application, we determine solutions for the case that $v_{t}$ is of the CESform given in (4), $A=B=1$ and $c^{0}=1-c^{1}$. That is, we consider specialized candidates who are better than their competitor in one field, and symmetrically-worse in the other field. Without loss of generality, assume that Candidate $i$ is better in the production of good $i$. To abbreviate the notation, let $r=c^{1}=1-c^{0}>1 / 2$. Thus, if $r$ is close to $1 / 2$, a candidate's advantage in his better field is very limited, while if $r$ is high, each candidate is a specialist in his strong field and a rookie in the other field.

We first determine the utility of a type $t$ voter if Candidate $i$ chooses the voter's most preferred policy. For example, let

$$
H\left(t, c^{0}\right)=\max _{a^{0}}\left\{(1-t)\left[r a^{0}\right]^{\rho}+t\left[(1-r)\left(1-a^{0}\right)\right]^{\rho}\right\}^{1 / \rho}
$$

be type $t$ 's utility when Candidate 0 takes the optimal action for $t$. Since $c^{1}=1-c^{0}$ it follows immediately 
that $H\left(t, c^{1}\right)=H\left(1-t, c^{0}\right)$ and that $a^{1}(t)=1-a^{0}(t)$.

By Theorem 5, the equilibrium is characterized by a cutoff voter $\bar{t}$ who is indifferent between the candidates' proposed policies: All types $t<\bar{t}$ vote for Candidate 0 and all types $t>\bar{t}$ vote for Candidate 1 . To determine $\bar{t}$, we solve the equation $H\left(\bar{t}, c^{0}\right)=H\left(\bar{t}, c^{1}\right)$. Since $H\left(t, c^{1}\right)=H\left(1-t, c^{0}\right)$, it follows that $\bar{t}=0.5$ is the unique solution. Solving (6) for $\bar{t}=1 / 2$ yields

$$
\bar{a}^{0}=\frac{1}{1+\left(\frac{1-r}{r}\right)^{\frac{\rho}{1-\rho}}}, \quad \bar{a}^{1}=\frac{\left(\frac{1-r}{r}\right)^{\frac{\rho}{1-\rho}}}{1+\left(\frac{1-r}{r}\right)^{\frac{\rho}{1-\rho}}}
$$

as the policy choices in the only possible pure strategy Nash equilibrium. The resulting production levels are

$$
\bar{x}_{0}^{0}=\bar{x}_{1}^{1}=\frac{r}{1+\left(\frac{1-r}{r}\right)^{\frac{\rho}{1-\rho}}}, \bar{x}_{1}^{0}=\bar{x}_{0}^{1}=\frac{(1-r)\left(\frac{1-r}{r}\right)^{\frac{\rho}{1-\rho}}}{1+\left(\frac{1-r}{r}\right)^{\frac{\rho}{1-\rho}}} .
$$

Given $\bar{x}^{0}$ and $\bar{x}^{1}$ it is indeed optimal for all citizens $t<\bar{t}$ to vote for Candidate 0 and for all citizens $t>\bar{t}$ to vote for Candidate 1. It remains to prove that we have an equilibrium.

Consider possible deviations by Candidate 1. Given the definition of $H\left(t, c^{i}\right)$, it is not possible for Candidate 1 to change his policy and attract a set of citizens $[\hat{t}, 1]$ where $\hat{t}<1 / 2$. The reason is that any deviation of Candidate 1 from (7) means that voter $\vec{t}$ 's utility from Candidate 1 decreases, so that he now strictly prefers Candidate 0 (and thus cannot be a part of Candidate 1's support coalition any more).

Thus, it remains to show that there is no profitable deviation by Candidate 1 that is attractive only to a subset of citizens to the left of $\bar{t}$. Since we prove that the set of citizens who vote for a particular candidate must be an interval, it is sufficient to show that type $t=0$ would never vote for Candidate 1 if Candidate 0 sticks with $\bar{x}^{0}$. In the proof of Theorem 5 we show that this is the case as long as the goods are sufficiently substitutable. We now directly determine the bound on substitutability.

The maximum amount of good 0 that Candidate 1 can provide is $(1-r)$. Thus, as long as $x_{0}^{0} \geq 1-r$, type 0 always votes for Candidate 0 . Solving this inequality yields

$$
\rho \geq \frac{\ln (2 r-1)-\ln (1-r)}{\ln (2 r-1)-\ln (r)}
$$

Because of symmetry, the same condition applies for deviations by Candidate 0 . The fact that $r>1 / 2$ implies that $\rho=1$ always satisfies (9). Furthermore, if candidates differ more from each other (i.e., $r$ increases), the right-hand side of (9) strictly decreases, and it is therefore easier to guarantee existence of a pure strategy equilibrium. As $r \rightarrow 1$, the right-hand side converges to $-\infty$ and existence is guaranteed even if substitutability between the goods is poor.

Note that (9) is a sufficient, but not necessary, condition. Remember that any deviation by Candidate 1 that attempts to attract voter 0 will lose the middle. Thus, even if there exists a deviation that would attract voter 0 , such a deviation would decrease the winning probability, if the median voter is expected to be 
close to $t=0.5$. However, (9) is the weakest condition that guarantees existence for any arbitrary type distribution. One can check that (9) is somewhat weaker than (5). The reason is that in this application we can determine closed form solutions for $\bar{x}^{0}$ and $\bar{x}^{1}$.

Theorem 5 shows that Candidate 0 produces more good 0 and less of good 1 compared to Candidate 1 . This can be immediately verified from (8). We can also compare the equilibrium spending allocations. If $\rho>0$, then $\bar{a}^{0}-\bar{a}^{1}>0$; that is, Candidate 0 allocates more resources to good 0 , thus endogenously furthering his exogenous advantage in the production of this good. Symmetrically, Candidate 1 focuses more resources on good 1 . Hence, when the public goods are relatively well-substitutable in the utility functions of voters, candidates take positions (i.e., spending proposals) that put emphasis on those policies in which they are already stronger than their opponent. Moreover, the more specialized the two candidates are (i.e., if $r$ is increased), the larger the difference in the proposed budget allocations. In the Cobb-Douglas case, $\rho=0$, both candidates choose the same spending allocation, independently of productivity differences. When $\rho<0$ (i.e., the two goods are relatively poor substitutes in the utility of voters), then $\bar{a}^{0}<\bar{a}^{1}$. That is, candidates attempt to partially compensate for the disadvantage they have in the production of their weaker good by allocating more money to this good.

\subsubsection{Interpretation}

Theorem 5 provides a novel explanation of equilibrium policy divergence and issue ownership. We will now discuss the relation between our model and previous literature on this subject. In his seminal article on issue ownership, Petrocik (1996), p.830, argues that (moderate) voters are "inclined to view elections as choices about collective goods and resolving problems, and not about the specifics of the solution." Petrocik's (qualitative) theory of issue ownership contains several specific hypotheses. First, each party "owns" certain issues that it is expected to better able to handle than its opponent. ${ }^{12}$

Second, candidates focus their campaign efforts on issues that are advantageous to them, and voters who are more concerned about Democratic issues vote Democratic, and vice versa. The key objective of each campaign is therefore to strengthen the perceived importance of its issues in the voters mind, and differential issue weights are the main difference between different election years, while the "critical constants are the issue handling reputations of the parties" (p.826, 828). In other words, a Republican campaign would focus on convincing the voters that terrorism and national security are really important issues.

Third, Petrocik argues that candidates cannot simply copy the recipes of the other party. "A Democrat's promise to attack crime by hiring more police, building more prisons and punishing with longer sentences would too easily be trumped by greater GOP enthusiasm for such solutions. [...] Candidates respond thus because $[\ldots]$ to do otherwise would advantage their opponent".

\footnotetext{
${ }^{12}$ For an empirical analysis of which issues are owned by Democrats and Republicans, see Petrocik's case study of the 1980 presidential campaign, and also Egan (2008) and Petrocik, Benoit, and Hansen (2003).
} 
The differential skills model predicts exactly this type of behavior. Voters who care strongly about those goods for which Candidate $i$ has a production advantage will, in equilibrium, strictly prefer Candidate $i$. Candidates cannot effectively compete for those voters who have a preference for the public good in which their opponent has an advantage by adopting a platform that proposes to provide more of that good. Indeed, we have argued above that small policy changes aimed to please marginal supporters of the opponent would always lose rather than win supporters in the differential skills model. This contrasts sharply with the standard Downsian model: There, assuming that candidates are initially located at different positions, adopting a platform closer to the platform of the opponent always increases the set of types who support a candidate.

Furthermore, even if the likely distribution of voter preferences is advantageous to the competitor in a particular election year, a candidate cannot successfully copy the platform of his competitor. A persistent change in the distribution over voter preference distributions has no immediate effect on the platforms that both parties select. Rather, a change of the voter preference distribution which makes it more likely, say, that the median type puts a higher emphasis on economic matters rather than national defense would just increase the probability that a Democrat wins. Republicans cannot successfully "fake" being Democrats by adopting "their" platform, and vice versa.

In a dynamic setting, these arguments would apply for the first elections following a persistent shift in the voter preference distribution. Over the long run, parties can probably "re-invent" themselves, in the sense that parties can affect their perceived strengths and weaknesses. For example, consider the Labour Party in the UK which lost power in 1979; it appears plausible that this was due to a fundamental and persistent change in the preference distribution of voters (say, more emphasis on economic growth relative to social justice). In the initial period after the loss, the party is stuck with its previously successful leaders who are specialists in social justice. During this time, we would expect that party platforms change very little, and popular support for the party is correspondingly reduced. Over the long term, however, the party may foster the development of new leaders who specialize more in being able to deliver on economic growth (while being weaker on social justice). Only when these new leaders are in place, then it starts to make sense to adjust the party platform correspondingly, and the party is eventually ripe for a return to power.

Finally, since candidates in the differential skills model have no opportunity to gain votes through pandering to marginal supporters of their opponent, an attractive option for a campaign may be to persuade voters that the issue in which the candidate has an advantage is "really important" (in the sense of trying to influence the $t$ in voters' utility functions). In contrast, in a standard Downsian model, trying to influence the distribution of voter ideal points has no benefit for a candidate who is interested only in winning. 


\section{Efficiency}

In the preceding sections, we have derived conditions under which equilibria with convergence or divergence exist. In this section, we turn to the normative properties of equilibrium. We first introduce the concept of competition efficiency. Intuitively, we ask whether a social planner could improve upon the equilibrium by selecting a platform for each candidate. By improving upon the equilibrium, we mean that a majority of the voters are made better off in a majority of states. Democracy is characterized by a "dictatorship of the majority", in the sense that a majority of people can impose a policy on all citizens. The relevant question for the effectiveness of a democracy is then whether the entirety of the political process (including the platform choice by candidates) leads to an outcome that is desirable for a majority.

To define our concept formally, first recall that $W^{i}\left(\omega, a^{0}, a^{1}\right)$ is Candidate $i$ 's winning probability. We can now map each pair of policy platforms into the implemented policy in state $\omega$, and hence into utility allocations to voters. Let $Q\left(\omega, \hat{a}^{0}, \hat{a}^{1}, a^{0}, a^{1}\right)$ denote the number of voters in state $\omega$ who prefer the policy that results if candidates choose platforms $\left(\hat{a}^{0}, \hat{a}^{1}\right)$ rather than $\left(a^{0}, a^{1}\right)$.

$$
\begin{aligned}
Q\left(\omega, \hat{a}^{0}, \hat{a}^{1}, a^{0}, a^{1}\right) & \left.=W^{0}\left(\omega, a^{0}, a^{1}\right)\right) W^{0}\left(\omega, \hat{a}^{0}, \hat{a}^{1}\right) \#\left(\left\{\ell \mid u^{\ell}\left(\omega, \hat{a}^{0}\right) \geq u^{\ell}\left(\omega, a^{0}\right)\right\}\right) \\
& \left.+W^{0}\left(\omega, a^{0}, a^{1}\right)\right) W^{1}\left(\omega, \hat{a}^{0}, \hat{a}^{1}\right) \#\left(\left\{\ell \mid u^{\ell}\left(\omega, \hat{a}^{1}\right) \geq u^{\ell}\left(\omega, a^{0}\right)\right\}\right) \\
& \left.+W^{1}\left(\omega, a^{0}, a^{1}\right)\right) W^{0}\left(\omega, \hat{a}^{0}, \hat{a}^{1}\right) \#\left(\left\{\ell \mid u^{\ell}\left(\omega, \hat{a}^{0}\right) \geq u^{\ell}\left(\omega, a^{1}\right)\right\}\right) \\
& \left.+W^{1}\left(\omega, a^{0}, a^{1}\right)\right) W^{1}\left(\omega, \hat{a}^{0}, \hat{a}^{1}\right) \#\left(\left\{\ell \mid u^{\ell}\left(\omega, \hat{a}^{1}\right) \geq u^{\ell}\left(\omega, a^{1}\right)\right\}\right) .
\end{aligned}
$$

We call a pair of policies "competition-efficient" if it is more likely than not that a majority of citizens prefer the implemented policy given platforms $\left(a^{0}, a^{1}\right)$ to the implemented policy given any other pair of platforms, $\left(\hat{a}^{0}, \hat{a}^{1}\right)$.

\section{Definition 3 A pair of policies $\left(a^{0}, a^{1}\right)$ is competition-efficient if and only if}

$$
\mu\left(\left\{\omega \mid Q\left(\omega, a^{0}, a^{1}, \hat{a}^{0}, \hat{a}^{1}\right) \geq Q\left(\omega, \hat{a}^{0}, \hat{a}^{1}, a^{0}, a^{1}\right)\right\}\right) \geq \mu\left(\left\{\omega \mid Q\left(\omega, \hat{a}^{0}, \hat{a}^{1}, a^{0}, a^{1}\right) \geq Q\left(\omega, a^{0}, a^{1}, \hat{a}^{0}, \hat{a}^{1}\right)\right\}\right)
$$

for all $\left(\hat{a}^{0}, \hat{a}^{1}\right) \in\left(A^{0}, A^{1}\right)$.

Our competition-efficiency concept is a very weak notion of efficiency. Alternatively, one could adopt a utilitarian notion, i.e. adding up (expected) utilities of voters. However, it is already well-known from the median voter model under certainty that the equilibrium fails this notion of utilitarian optimality: Candidates care about winning a majority and thus maximize the utility of the median voter, rather than the average utility of voters. In contrast, the equilibrium of the median voter theorem under certainty satisfies our notion of competition-efficiency, because there is no way how a social planner could make a majority of the electorate better off (in the only state of the world). Therefore, results of competitioninefficiency in our model highlight the additional complicating role of uncertainty about voter preferences for the efficiency of the political process. 
Also note that candidates only care that they receive a majority of votes, but do not care how large this majority is. For this reason, our concept only focuses on whether it would be possible to make a majority of the electorate better off in a majority of states (weighted by probability), but does not differentiate according to how large this majority is.

We first show that, if the candidates have the same fixed positions and choose exactly the same policies, then the equilibrium is generically competition-inefficient.

Theorem 6 For a generic set of voting games the following holds: Any pair of strategies $\left(a^{*}, a^{*}\right)$ is not competition-efficient.

Intuitively, offering different choices to voters is beneficial in the presence of uncertainty. While it may be the case that $a^{*}$ is the preferred choice by citizens in a majority of states, offering an additional policy $\hat{a}$ that is preferred to $a^{*}$ even with a small probability has the potential of making a majority better off, while there is no offsetting cost (i.e., a state in which the majority would be worse off. The following result follows immediately from Theorem 6 and Theorem 3.

Corollary 1 If all voters have UCR preferences, then any strict Nash equilibrium is generically not competition-efficient.

As a simple illustration, suppose that candidates have the same fixed characteristic (i.e., $c^{0}=c^{1}$ ) and that there is just one binary policy issue, i.e., $A=\{0,1\}$. Furthermore, suppose that the probability that a majority prefers position 1 is 60 percent, while the majority prefers position 0 with the complementary probability. In the strict equilibrium, both candidates choose position 1 (which gives each of them a probability $1 / 2$ of winning; a deviation to position 0 would lower that probability to 0.4 ). Clearly, in this equilibrium, there is a 40 percent chance that the polity is stuck with the minority position. In contrast, the competition-efficient pair of policies is for one candidate to take position 0 and his opponent to take position 1, so that the majority always gets their preferred choice. The cause of the inefficiency is the duplication of policies by the two candidates in equilibrium, which deprives voters of another policy choice.

In contrast, if candidates differ in their fixed characteristics, then equilibria can be competitionefficient, because the two candidates are not the same, even if candidates converge to the same policies. The following Theorem 7 provides conditions under which equilibria are competition-efficient.

\section{Theorem 7 Suppose that}

1. The utility function of voter $\ell$ is given by $u^{\ell}(c, a, \omega)=g\left(f(c, \omega), h_{\ell}(a)\right)$, where $g: \mathbb{R}_{+}^{2} \rightarrow \mathbb{R}$ is continuous and strictly increasing in both arguments.

2. There exist $\omega \in \Omega$ such that $f\left(c^{0}, \omega\right)=f\left(c^{1}, \omega\right)$. 
3. There exists $a^{*}$ such that $\#\left\{\ell \mid h_{\ell}\left(a^{*}\right) \geq h_{\ell}(a)\right\}>\#\left\{\ell \mid h_{\ell}(a) \geq h_{\ell}\left(a^{*}\right)\right\}$ for all $a \in A$.

Then $\left(c^{0}, a^{*}\right),\left(c^{1}, a^{*}\right)$ is a Nash equilibrium, and the equilibrium is competition-efficient.

The first condition secures that voters have UCR preferences, the second one secures that there is a state in which both candidates are competitive (provided that they choose the same policy position), and the third one secures that there exists a platform that is majority-preferred to any other platform. A simple example where these conditions are satisfied is a standard one-dimensional setting with uncertainty about the candidates' valences, but no uncertainty about the preferred policy of the median voter. In such a model, both candidates maximize their respective winning probabilities by choosing the median voter's preferred position. A social planner would do exactly the same, as the relevant uncertainty is only about the evaluation about the candidates' (already differentiated) fixed characteristics.

Finally, consider competition-efficiency in the differential skills model of Section 4.2. If the median of $t_{m}(\omega)$ is substantially greater than $\bar{t}$, then the candidates (and, in particular, Candidate 1, the likely election winner in this case) could almost certainly increase the utility of a majority of voters. The reason for this inefficiency is that both candidates focus on the "swing state" (where $t_{m}(\omega)=\bar{t}$ ) in which both of them are competitive. There is no benefit for the likely election winner to focus on those likely states of the world where a majority would like him to provide more good $x_{1}$, because he wins in those states anyway.

Even if $t_{m}(\omega)$ is distributed symmetrically around $\bar{t}$, the equilibrium is competition-inefficient, because there is too little divergence. To see this, note that both candidates appeal to voter $\bar{t}$. Suppose a social planner could marginally and symmetrically increase $a^{0}$ and decrease $a^{1}$ so that the cutoff type $t^{*}$ remains indifferent between the two candidates; thus, in every state, the identity of the winning candidate is exactly the same as in the equilibrium. If $t_{m}(\omega)<\bar{t}$, then Candidate 0 wins, and all types smaller than $t^{*}$ (thus, a majority) prefer the increased $a^{0}$ over the equilibrium value of $a^{0}$. Similarly, if $t_{m}(\omega)>\bar{t}$, then types with $t>\bar{t}$ are in the majority, and all of them prefer the increased level of $1-a^{1}$ (i.e., production of good $x_{1}$ ). Therefore, since a strict majority of voters is almost certainly either greater than $\bar{t}$ or smaller than $\bar{t}$, a social planner could almost certainly increase the utility of a majority of voters by increasing $a^{0}$ and decreasing $a^{1}$ marginally.

\section{Previous Literature}

The platform choice of candidates for political office is one of the major areas of interest in formal models of politics. There is a huge literature on the topic of policy convergence or divergence in one-dimensional models (or models with one policy dimension and one valence dimension). For excellent reviews of this area, see, e.g., Osborne (1995) and Grofman (2004). 
Relative to this literature, our paper has two fundamental innovations. First, while almost the entire existing literature on candidate platform choice deals with a one-dimensional policy space in which voters have single-peaked preferences, we allow for much more general voter preferences in a multidimensional framework. In our model, complementarities between policies on different issues, or between policies and candidate characteristics, can be analyzed. As discussed above in Section 4.2, this point can be linked to the (mostly informal) literature on issue ownership. To our knowledge, the only other theoretical model in which complementarities between different issues play a key role is Ahn and Oliveros (2008), who study a model of voting on different referendum proposals. Voting occurs simultaneously for all proposals, and voters' preferences are not separable across issues, but rather depend on the whole vector of proposals that pass. In contrast to our model, platform proposals are entirely exogenous in Ahn and Oliveros (2008), and their focus is on showing the existence of a voting equilibrium.

While we introduce finiteness of $A$ in the first part of the paper for technical convenience, this assumption is also natural and increases the chance that a pure strategy equilibrium exists for generic preference distributions. In this respect, our paper is related to a line of research on structure-induced stability, started by Shepsle (1979) and Shepsle and Weingast (1981) (see also Tullock (1981)), which focuses on legislatures. In this literature, legislative institutions restrict the set of policies that can be proposed.

Second, by interpreting (some) fixed characteristics as already committed policy positions, our model provides a middle ground between Downsian models, in which candidates are free to choose any position, and the citizen candidate model, in which no commitment is possible. In the citizen candidate literature pioneered by Osborne and Slivinski (1996) and Besley and Coate (1997), candidates are policy motivated and cannot commit to any other position than their ideal one. While the citizen candidate model can, in principle, handle multiple policy dimensions, most papers in this literature only look at a standard onedimensional framework.

There is a large literature that tries to explain, within the Downsian model, the empirical observation that candidates often propose considerably divergent policies. Candidates may diverge even though this decreases their winning probability, because they care about the implemented policy (see, e.g., Wittman (1983), Calvert (1985), Roemer (1994), Martinelli (2001), Gul and Pesendorfer (2009)). In contrast, in our model, divergence may increase a candidate's probability of winning.

Some models obtain policy divergence with office-motivated candidates in a one-dimensional setting with incomplete information among voters about candidate characteristics (e.g. Callander (2008)) or among candidates about the position of the median voter (Castanheira (2003), Bernhardt, Duggan, and Squintani (2006)). Another branch of literature on divergence with office motivation, which is less directly related to our paper, explains policy divergence as entry deterrence by two dominant parties (e.g., Palfrey (1984), Callander (2005)).

Adams and Merrill (2003) analyze a model in which voters have, in addition to preferences over 
policy positions from the $[0,1]$ interval, "non-policy preferences" over the two candidates, which corresponds to different fixed positions in our setting. They assume that voters may abstain due to being almost indifferent between candidates, or due to "alienation" (if their preferred candidate does not provide them with sufficient utility). While there is still policy convergence in this model if voters only abstain from indifference (see also Erikson and Romero (1990)), they show that abstention from alienation may provide an incentive for strong divergence. We show that abstention due to alienation leads to non-UCR preferences, which is the fundamental reason for divergence in Adams and Merrill (2003).

\section{Conclusion}

We have developed a framework in which candidates differ in their fixed characteristics, and choose policy positions in order to maximize their respective winning probability. The model is considerably more general than standard models of candidate competition, because we allow for voters to have general preferences over the vectors of characteristics and policies. We characterize the class of uniform candidate ranking (UCR) preferences. If voters have UCR preferences, then there is an incentive for candidates to converge in policies. This result provides a general class of voter preferences under which to expect equilibrium convergence such as it happens in the Downsian model or the probabilistic voting model.

However, there are also interesting and relevant settings in which voters have non-UCR-preferences. Our framework is the first model in which the issue of complementarity between a candidate's immutable characteristics and the candidate's policy choices can be studied. In particular, we focus on the case that candidates have differential skills in implementing policy in different policy fields. This model naturally leads to what Petrocik (1996) and others have called "issue ownership": Both candidates have policy fields in which they are preferred by voters, and their platforms generally do not converge. Those voters who care predominantly about "Democratic issues" vote for the Democrat and vice versa. It is in principle possible in our model for a Democratic candidate to adopt a Republican platform and vice versa, such imitation is not electorally beneficial for the candidates and does not occur in equilibrium. While there is a "cutoff voter" whose utility is maximized by both candidates, this cutoff voter is generally not the median voter (or the "median median", if there is uncertainty about the location of the median voter). Moreover, the identity of the cutoff voter is independent of the distribution of voter preferences and, as a consequence, purely office-motivated candidates appear rigid when the distribution of voter preferences changes. These effects are, to our knowledge, novel in any formal model of candidate platform choice.

Our final contribution in this paper is normative. We define the notion of competition-efficiency. A pure strategy equilibrium is competition-efficient if there is no other pair of feasible positions for the two candidates that is more likely to make a majority of people better off than worse off. The equilibrium in a standard one-dimensional Downsian model without uncertainty is competition-efficient. In contrast, there are two forces that lead to competition-inefficiency in our model. First, if the equilibrium features 
convergence, then voters have a limited choice in the election. In particular, if candidates do not differ in fixed characteristics, then both candidates offer voters exactly the same policies in the generic equilibrium, while a social planner would prefer to offer voters a non-trivial choice, provided that there is uncertainty about the majority-preferred policy. In contrast, if candidates differ in fixed characteristics, then even an equilibrium with policy convergence may be competition-efficient. Second, candidates focus on the effect of their policy choice on swing voters and in states of the world where the race is close. It is not guaranteed that a policy choice that is successful for candidates with respect to these objectives is also socially desirable. 


\section{Appendix}

Proof of Theorem 1. It is sufficient to prove the theorem for an arbitrary $\omega$; from now on, we suppress $\omega$ in the notation (so we write $g(f(c), b)$ instead of $g(f(c), b, \omega)$ ).

We start by proving that statement 2 implies statement 1 . Let $(c, b) \geq_{\omega}\left(c^{\prime}, b\right)$. Then $g(f(c), b) \geq$ $g\left(f\left(c^{\prime}\right), b\right)$. Since $g$ is strictly monotone in the first argument this implies $f(c) \geq f\left(c^{\prime}\right)$. Again, strict monotonicity implies $g\left(f(c), b^{\prime}\right) \geq g\left(f\left(c^{\prime}\right), b^{\prime}\right)$, which implies $\left(c, b^{\prime}\right) \geq_{\omega}\left(c^{\prime}, b^{\prime}\right)$, i.e., UCR holds.

We now prove that statement 1 implies statement 2.

Define preferences $\geq_{\omega}^{C}$ on $C$ as follows: $c \geq_{\omega}^{C} c^{\prime}$ if there exists $a \in A$ with $(c, a) \geq_{\omega}\left(c^{\prime}, a\right)$. Note that these preferences are well defined. In particular, the ability to uniformly rank candidates in state $\omega$ implies that $\left(c, a^{\prime}\right) \geq_{\omega}\left(c^{\prime}, a^{\prime}\right)$ for any $a^{\prime} \in A$. Further preferences $\geq_{\omega}^{C}$ are complete since $\geq_{\omega}$ are complete and therefore either $(c, a) \geq_{\omega}\left(c^{\prime}, a\right)$ or $\left(c^{\prime}, a\right) \geq_{\omega}(c, a)$ must be satisfied. In the first case $c \geq_{\omega}^{C} c^{\prime}$ while in the second case $c^{\prime} \geq_{\omega}^{C} c$. Transitivity of $\geq_{\omega}^{C}$ follows also immediately from transitivity of $\geq_{\omega}$. In particular, suppose that $c \geq_{\omega}^{C} c^{\prime}$ and $c^{\prime} \geq_{\omega}^{C} c^{\prime \prime}$. Then for any $a \in A$ we get $(c, a) \geq_{\omega}\left(c^{\prime}, a\right)$ and $\left(c^{\prime}, a\right) \geq_{\omega}\left(c^{\prime \prime}, a\right)$. Thus, $(c, a) \geq_{\omega}\left(c^{\prime \prime}, a\right)$, which implies that $c \geq_{\omega}^{C} c^{\prime \prime}$.

Since $C$ is finite there exists a utility function $f$ that describes preferences $\geq_{\omega}^{C}$, i.e., $f(c) \geq f\left(c^{\prime}\right)$ if and only if $c \geq_{\omega}^{C} c^{\prime}$. Let $Y=f(C)$ and $c, c^{\prime} \in f^{-1}(y)$ for some $y \in Y$. We now define preferences on $Y \times A$ as follows: $(y, a) \geq_{\omega}^{\prime}\left(y^{\prime}, a^{\prime}\right)$ if and only if there exist $c \in f^{-1}(y)$ and $c^{\prime} \in f^{-1}\left(y^{\prime}\right)$ with $(c, a) \geq_{\omega}\left(c^{\prime}, a^{\prime}\right)$.

To show that these preferences are well defined, let $\hat{c} \in f^{-1}(y)$ and $\hat{c}^{\prime} \in f^{-1}\left(y^{\prime}\right)$. We must show that $(\hat{c}, a) \geq_{\omega}\left(\hat{c}^{\prime}, a^{\prime}\right) . f(c)=f(\hat{c})$ and $f\left(c^{\prime}\right)=f\left(\hat{c}^{\prime}\right)$ and the fact that $f$ is a utility function for $\geq_{\omega}^{C}$ implies that $(c, a) \sim_{\omega}(\hat{c}, a)$ and $\left(c^{\prime}, a^{\prime}\right) \sim_{\omega}\left(\hat{c}^{\prime}, a^{\prime}\right)$. Thus, $(\hat{c}, a) \sim(c, a) \geq_{\omega}\left(c^{\prime}, a^{\prime}\right) \sim\left(\hat{c}^{\prime}, a^{\prime}\right)$.

Completeness of preferences $\geq_{\omega}^{\prime}$ follows immediately from completeness of $\succeq_{\omega}$. To prove transitivity, let $(y, a) \geq_{\omega}^{\prime}\left(y^{\prime}, a^{\prime}\right)$ and $\left(y^{\prime}, a\right) \geq_{\omega}^{\prime}\left(y^{\prime \prime}, a^{\prime}\right)$. This implies $(c, a) \geq_{\omega}\left(c^{\prime}, a^{\prime}\right)$ and $\left(\hat{c}^{\prime}, a^{\prime}\right) \geq_{\omega}\left(c^{\prime \prime}, a^{\prime \prime}\right)$, where $c \in f^{-1}(y), c^{\prime}, \hat{c}^{\prime} \in f^{-1}\left(y^{\prime}\right)$ and $c^{\prime \prime} \in f^{-1}\left(y^{\prime \prime}\right)$. Since $c^{\prime}, \hat{c}^{\prime} \in f^{-1}\left(y^{\prime}\right)$ we get $\left(c^{\prime}, a^{\prime}\right) \sim_{\omega}\left(\hat{c}^{\prime}, a^{\prime}\right)$. Thus, transitivity of $\geq_{\omega}$ implies $(c, a) \geq_{\omega}\left(c^{\prime \prime}, a^{\prime \prime}\right)$, and therefore $(y, a) \geq_{\omega}^{\prime}\left(y^{\prime \prime}, a^{\prime \prime}\right)$.

Next, note preferences $\geq_{\omega}^{\prime}$ are strictly monotone in $y$. In particular, let $(y, a),\left(y^{\prime}, a\right) \in Y \times A$ with $y>y^{\prime}$. Let $c \in f^{-1}(y)$ and $c^{\prime} \in f^{-1}\left(y^{\prime}\right)$. Because $f$ is a utility function describing preferences on $C$ it follows that $c>_{\omega}^{C} c^{\prime}$. This, in turn implies $(c, a)>\left(c^{\prime}, a\right)$, and therefore $(y, a)>_{\omega}^{\prime}\left(y^{\prime}, a\right)$.

Because $Y \times A$ is finite there exists a utility function $g$ that describes preferences $\geq_{\omega}^{\prime}$. Strict monotonicity of preferences in $y$ implies that $g$ is strictly monotone in $y$. Finally, $u(a)=g(f(c), a)$ is a utility function that describes preferences $\geq_{\omega}$.

Proof of Theorem 2. If $a^{0}=a^{1}$, then $c^{0}=c^{1}$ and reflexivity of preferences imply that all voters are indifferent between the candidates. Thus, the winning probabilities are 0.5 . Let $\left(a^{0}, a^{1}\right)$ be a Nash 
equilibrium. If Candidate $j$ 's payoff were strictly less than 0.5 in this equilibrium, then Candidate $j$ could increase the payoff to 0.5 by using the same policy as the other agent. However, since $W^{1}\left(\omega, a^{0}, a^{1}\right)=$ $1-W^{0}\left(\omega, a^{0}, a^{1}\right)$ this implies $\int W^{j}\left(\omega, a^{0}, a^{1}\right) d \mu(\omega)=0.5$, i.e., in equilibrium $\left(a^{0}, a^{1}\right)$ each candidate's winning probability is 0.5 .

We now prove that $\left(a^{1}, a^{1}\right)$ is Nash equilibrium. Suppose by way of contradiction that there exists a deviation $\tilde{a}^{i}$ that makes Candidate $i$ strictly better off. If $i=0$ then Candidate 0 would have used $\tilde{a}^{0}$ against $a^{1}$ thereby increasing his payoff, resulting in a winning probability that is strictly greater than 0.5 . This contradicts the assumption that $\left(a^{0}, a^{1}\right)$ is a Nash equilibrium (as the candidates' winning probability in $\left(a^{0}, a^{1}\right)$ is 0.5$)$. Thus, we can assume that $i=1$, i.e., $\tilde{a}^{1}$ played against $a^{1}$ results in a ex-ante winning probability that is strictly greater than 0.5 . However, $c^{0}=c^{1}$ implies that $W^{0}\left(\omega, a^{0}, a^{1}\right)=W^{1}\left(\omega, a^{1}, a^{0}\right)$. Thus, $0.5<\int W^{1}\left(\omega, a_{1}, \tilde{a}^{1}\right) d \mu(\omega)=\int W^{0}\left(\omega, \tilde{a}^{1}, a^{1}\right) d \mu(\omega) \leq 0.5$, where the last inequality follows since $\left(a^{0}, a^{1}\right)$ is a Nash equilibrium with winning probabilities 0.5 . This contradiction proves that $\left(a^{1}, a^{1}\right)$ is a Nash equilibrium. Similarly, it follows that $\left(a^{0}, a^{0}\right)$ is a Nash equilibrium.

Now suppose that $\left(a^{0}, a^{1}\right)$ is a strict Nash equilibrium. If $a^{0} \neq a^{1}$ then the previous argument implies that $\left(a^{0}, a^{0}\right)$ is also a Nash equilibrium resulting in the same winning probability, which contradicts the assumption that $\left(a^{0}, a^{1}\right)$ is strict. Thus, $a^{0}=a^{1}=\bar{a}$. Suppose by way of contradiction that there exists another pure strategy Nash equilibrium $\left(a^{\prime}, a^{\prime}\right)$, where $a^{\prime} \neq \bar{a}$ (because of the first part of the proof we can assume that both candidates use the same strategy). Since the equilibrium $(\bar{a}, \bar{a})$ is strict we get $0.5=\int W^{0}(\omega, \bar{a}, \bar{a}) d \mu(\omega)>\int W^{0}\left(\omega, a^{\prime}, \bar{a}\right) d \mu(\omega)$. Thus, $W^{0}+W^{1}=1$ implies $\int W^{1}\left(\omega, a^{\prime}, \bar{a}\right) d \mu(\omega)>$ 0.5 . Hence, $\left(a^{\prime}, a^{\prime}\right)$ is not a Nash equilibrium since there exists a profitable deviation for Candidate 1 , a contradiction.

Finally, suppose that there exists a mixed strategy equilibrium. Without loss of generality we can assume that Candidate 0 mixes with strictly positive probability. The argument in the previous paragraph implies that $\int W^{1}(\omega, a, \bar{a}) d \mu(\omega) \geq 0.5$ for all $a \in A$, and that the inequality is strict for $a \neq \bar{a}$. Similarly, $\int W^{0}(\omega, \bar{a}, a) d \mu(\omega) \geq 0.5$ for all $a \in A$. The first inequality and the fact that Candidate 0 mixes imply that by choosing $a^{1}=\bar{a}$ with probability 1 , Candidate 1 gets a winning probability that is strictly greater than 0.5 . The second inequality implies that Candidate 0 's winning probability must be at least 0.5 . Thus, the winning probabilities add to a number strictly greater than 1 , a contradiction. Hence, there does not exist a mixed strategy equilibrium.

Proof of Theorem 3. Suppose by way of contradiction that there exists a strict Nash equilibrium $\left(a^{0}, a^{1}\right)$ with $a^{0} \neq a^{1}$. Then

$$
\begin{aligned}
& \int W^{0}\left(\omega, a^{0}, a^{1}\right) d \mu(\omega)>\int W^{0}\left(\omega, a^{1}, a^{1}\right) d \mu(\omega), \\
& \int W^{1}\left(\omega, a^{0}, a^{1}\right) d \mu(\omega)>\int W^{1}\left(\omega, a^{0}, a^{0}\right) d \mu(\omega) .
\end{aligned}
$$


Next, note that if preferences are UCR then $\left(c^{0}, a\right) \geq_{\omega}^{\ell}\left(c^{1}, a\right)$ if and only if $\left(c^{0}, a^{\prime}\right) \geq_{\omega}^{\ell}\left(c^{1}, a^{\prime}\right)$ for any citizen $\ell$ and for any state $\omega \in \Omega$. Thus, citizens' voting behavior is the same if both candidates choose $a$ or if both choose $a^{\prime}$. Thus, the winning probabilities do not change for candidates $j=1,2$, i.e.,

$$
W^{j}(\omega, a, a)=W^{j}\left(\omega, a^{\prime}, a^{\prime}\right), \text { for all } a, a^{\prime} \in A .
$$

(10), (12), and the fact that $W^{0}+W^{1}=1$ imply

$$
\int W^{1}\left(\omega, a^{0}, a^{1}\right) d \mu(\omega)<\int W^{1}\left(\omega, a^{1}, a^{1}\right) d \mu(\omega)=\int W^{1}\left(\omega, a^{0}, a^{0}\right) d \mu(\omega),
$$

But (13) contradicts (11). Thus, in any strict Nash equilibrium $a^{0}=a^{1}=a$.

Next, we prove uniqueness of the Nash equilibrium $(a, a)$. First, suppose that there exists another pure strategy Nash equilibrium $\left(a_{0}, a_{1}\right)$. Since the Nash equilibrium $(a, a)$ is strict, it follows that $a^{0}, a^{1} \neq a$. Further, $\int W^{1}(\omega, a, a) d \mu(\omega)>\int W^{1}\left(\omega, a, a^{1}\right) d \mu(\omega)$ and $\int W^{0}(\omega, a, a) d \mu(\omega)>\int W^{0}\left(\omega, a^{0}, a\right) d \mu(\omega)$. Since $W^{0}+W^{1}=1$ we get

$$
\begin{aligned}
& \int W^{0}(\omega, a, a) d \mu(\omega)<\int W^{0}\left(\omega, a, a^{1}\right) d \mu(\omega) ; \text { and } \\
& \int W^{1}(\omega, a, a) d \mu(\omega)<\int W^{1}\left(\omega, a^{0}, a\right) d \mu(\omega) .
\end{aligned}
$$

(14), (15) and the fact that $\left(a^{0}, a^{1}\right)$ is a Nash equilibrium implies

$$
\begin{aligned}
& \int W^{0}(\omega, a, a) d \mu(\omega)<\int W^{0}\left(\omega, a, a^{1}\right) d \mu(\omega) \leq \int W^{0}\left(\omega, a^{0}, a^{1}\right) d \mu(\omega) ; \\
& \int W^{1}(\omega, a, a) d \mu(\omega)<\int W^{1}\left(\omega, a^{0}, a\right) d \mu(\omega) \leq \int W^{0}\left(\omega, a^{0}, a^{1}\right) d \mu(\omega) .
\end{aligned}
$$

Since $W^{0}+W^{1}=1$, adding (16) and (17) yields a contradiction. Thus, the Nash equilibrium is unique among all pure strategy equilibria. The remainder of the proof, that there is no mixed strategy equilibrium, is identical to the last step in the proof of Theorem 2.

Proof of Theorem 4. We first show that $a^{0} \neq a^{1}$ implies that

$$
\int W_{t}^{i}\left(\omega, a^{0}, a^{1}\right) d \mu(\omega) \neq \int W_{t}^{i}\left(\omega, a^{0}, a^{0}\right) d \mu(\omega)
$$

for generic preference profiles $t \in T$.

Let $T\left(a^{0}, a^{1}\right)=\{t \in T \mid$ (18) holds $\}$. We must prove that $T\left(a^{0}, a^{1}\right)$ is an open and dense subset of $T$. To show that $T\left(a^{0}, a^{1}\right)$ is dense, let $\bar{t} \in T \backslash T\left(a^{0}, a^{1}\right)$. We must find a sequence $t^{\epsilon}$ in $T\left(a^{0}, a^{1}\right)$ that converges to $\bar{t}$.

Let $\tilde{\Omega}=\left\{\omega \mid W_{\bar{t}}^{0}\left(\omega, a^{0}, a^{1}\right)>W_{\bar{t}}^{0}\left(\omega, a^{0}, a^{0}\right)\right\}$. We first consider the case where $\mu(\tilde{\Omega})>0$. 
Clearly, $\mu(\tilde{\Omega})<1$, else (18) would be satisfied, which would imply that $\bar{t} \in T\left(a^{0}, a^{1}\right)$. Let $\bar{\omega} \in \Omega \backslash \tilde{\Omega}$. Since $\mu$ is non-atomic, there exist for every $\varepsilon>0$ a set $B_{\varepsilon} \subset \tilde{\Omega}$ with $0<\mu\left(B_{\varepsilon}\right)<\varepsilon$. Define a new preference profile $t^{\varepsilon}=\left(t_{1}^{\varepsilon}, \ldots, t_{L}^{\varepsilon}\right)$ by

$$
t_{i}^{\varepsilon}(\omega)= \begin{cases}t_{i}(\bar{\omega}) & \text { if } \omega \in B_{\varepsilon} \\ t_{i}(\omega) & \text { otherwise }\end{cases}
$$

Since $\int W_{\bar{t}}^{0}\left(\omega, a^{0}, a^{1}\right) d \mu(\omega)=\int W_{\bar{t}}^{0}\left(\omega, a^{0}, a^{0}\right) d \mu(\omega), W_{t^{\varepsilon}}^{0}\left(\omega, a^{0}, a^{1}\right)>W_{t^{\varepsilon}}^{0}\left(\omega, a^{0}, a^{1}\right)$ for all $\omega \in B_{\varepsilon}$ and $W_{t^{\varepsilon}}^{0}\left(\omega, a, a^{\prime}\right)=W_{\bar{t}}^{0}\left(\omega, a, a^{\prime}\right)$ for all $\omega \notin B_{\varepsilon}$ and all $a, a^{\prime} \in A$, it follows that $\int W_{t^{\varepsilon}}^{0}\left(\omega, a^{0}, a^{1}\right) d \mu(\omega)>$ $\int W_{t^{\varepsilon}}^{0}\left(\omega, a^{0}, a^{0}\right) d \mu(\omega)$. Since $W^{0}+W^{1}=1$ this implies $\int W_{t^{\varepsilon}}^{1}\left(\omega, a^{0}, a^{1}\right) d \mu(\omega)<\int W^{1} t^{\varepsilon}\left(\omega, a^{0}, a^{0}\right) d \mu(\omega)$, and hence $t^{\varepsilon} \in T\left(a^{0}, a^{1}\right)$ for all $\varepsilon>0$. Next, $t^{\varepsilon} \rightarrow \bar{t}$ as $\varepsilon \downarrow 0$ since preferences $t$ and $t^{\varepsilon}$ only differ on $B_{\varepsilon}$, a set with probability less than $\varepsilon$.

The same argument as above applies if $\mu\left(\left\{\omega \mid W_{\bar{t}}^{0}\left(\omega, a^{0}, a^{1}\right)<W_{\bar{t}}^{0}\left(\omega, a^{0}, a^{0}\right)\right\}\right)>0$. This leaves the case where

$$
W_{\bar{t}}^{0}\left(\omega, a^{0}, a^{1}\right)=W_{\bar{t}}^{0}\left(\omega, a^{0}, a^{0}\right) \text {, for } \mu \text { a.e. } \omega \text {. }
$$

Consider a utility function $u_{A}$ such that $u_{A}\left(a^{0}\right)>u_{A}(a)$ for all $a \neq a^{0}$. Define $u(c, a)=u_{A}(a)$ and $p \in P$ be the preferences described by $u$. Clearly, $p$ satisfies UCR and $u\left(c, a^{0}\right)>u\left(c^{\prime}, a^{1}\right)$ for all $c, c^{\prime} \in C$. Let $\Omega^{\prime}=\left\{\omega \mid W_{\bar{t}}^{0}\left(\omega, a^{0}, a^{1}\right) \leq 0.5\right\}$. Then $\mu\left(\Omega^{\prime}\right)>0$ since Candidate 1 wins with strictly positive probability. For $\varepsilon>0$ let $B_{\varepsilon} \subset \Omega^{\prime}$ with $0<\mu\left(B_{\varepsilon}\right)<\varepsilon$. Define a new preference profile $t^{\varepsilon}=\left(t_{1}^{\varepsilon}, \ldots, t_{L}^{\varepsilon}\right)$ by

$$
t_{i}^{\varepsilon}(\omega)= \begin{cases}p & \text { if } \omega \in B_{\varepsilon} \\ \bar{t}_{i}(\omega) & \text { otherwise }\end{cases}
$$

Then $W_{t^{\varepsilon}}^{0}\left(\omega, a^{0}, a^{1}\right)=1$ for all $\omega \in B_{\varepsilon}$ and $W_{t^{\varepsilon}}^{0}\left(\omega, a^{0}, a^{0}\right)=0.5$ for all $\omega \in B_{\varepsilon}$. Thus,

$$
\int_{B_{\varepsilon}} W_{t^{\varepsilon}}^{0}\left(\omega, a^{0}, a^{1}\right) d \mu(\omega)>\int_{B_{\varepsilon}} W_{t^{\varepsilon}}^{0}\left(\omega, a^{0}, a^{0}\right) d \mu(\omega)
$$

(19), (21) and the fact that $t^{\epsilon}$ and $t$ coincide on $\Omega \backslash B_{\varepsilon}$ imply $\int W_{t^{\varepsilon}}^{0}\left(\omega, a^{0}, a^{1}\right) d \mu>\int W_{t^{\varepsilon}}^{0}\left(\omega, a^{0}, a^{0}\right)$. Thus, $t^{\varepsilon} \in T\left(a^{0}, a^{1}\right)$, and as above it follows that $t^{\varepsilon}$ converges to $\bar{t}$ as $\varepsilon \downarrow 0$.

If Candidate 1 always loses, then $B_{\varepsilon}$ is any subset of $\Omega$ with $0<\mu\left(B_{\varepsilon}\right)<\varepsilon$. Let $p$ be the preferences described by $u(c, a)=u_{A}(a)$ where $u_{A}\left(a^{1}\right)>u_{A}(a)$ for all $a \neq a^{1}$. Define $t^{\epsilon}$ as in (20). Then it follows again that $t^{\epsilon} \in T\left(a^{0}, a^{1}\right)$ and that $t^{\varepsilon}$ converges to $\bar{t}$. Thus, $T\left(a^{0}, a^{1}\right)$ is a dense subset of $T$.

We next prove that $T\left(a^{0}, a^{1}\right)$ is open. Let $\delta=\min _{p \neq p^{\prime}} d\left(p, p^{\prime}\right)$. Then for $\varepsilon<\delta$ it follows that if $d_{T}\left(t, t^{\prime}\right)<\varepsilon$ then $t$ and $t^{\prime}$ only differ on a set $B \subset \Omega$ with $\mu(B)<\varepsilon$. As a consequence, the ex-ante expected winning probabilities can only change on $B$. If the difference in winning probabilities for $t$ is greater than $\varepsilon$, then any change of each winning probability of less than $\varepsilon$ will not result in equality in (18). 
Let $T^{\prime}=\bigcap_{a^{0}, a^{1}} T\left(a^{0}, a^{1}\right)$. Since there are only finitely many policies, it follows that $T^{\prime}$ is open and dense in $T$. It remains to prove that for all $t \in T^{\prime}$ any Nash equilibrium is strict.

If $a^{0}=a^{1}$ in the Nash equilibrium then strictness follows immediately from the fact that (18) holds for all $t \in T^{\prime}$. Thus, suppose that $a^{0} \neq a^{1}$. Then

$$
\int W_{t}^{0}\left(\omega, a^{0}, a^{1}\right) d \mu(\omega) \geq \int W_{t}^{0}\left(\omega, a^{1}, a^{1}\right) d \mu(\omega),
$$

because $\left(a^{0}, a^{1}\right)$ is a Nash equilibrium. Thus, (22) implies

$$
\int W_{t}^{1}\left(\omega, a^{0}, a^{1}\right) d \mu(\omega) \leq \int W_{t}^{1}\left(\omega, a^{1}, a^{1}\right) d \mu(\omega)=\int W_{t}^{1}\left(\omega, a^{0}, a^{0}\right) d \mu(\omega),
$$

where the inequality follows since $W_{t}^{0}+W_{t}^{1}=1$ and the equality since preferences satisfy UCR (and hence (12) holds). However, since $\left(a^{0}, a^{1}\right)$ is a Nash equilibrium no deviation can make Candidate 1 strictly better off. Thus, (23) holds with equality. Thus, $W_{t}^{0}+W_{t}^{1}=1$ implies

$$
\int W_{t}^{0}\left(\omega, a^{0}, a^{1}\right) d \mu(\omega)=\int W_{t}^{0}\left(\omega, a^{0}, a^{0}\right) d \mu(\omega),
$$

This, however, contradicts the assumption that $t \in T^{\prime}$.

The following Lemma is used in the proof of Theorem 5.

Lemma 1 Let $x^{0}, x^{1}$ be the amount of public goods offered by the two candidates. Let $D=\left\{t \mid v_{t}\left(x^{j}\right) \geq\right.$ $\left.v_{t}\left(x^{-j}\right)\right\}$ be the set of types that weakly prefer $x^{j}$ to $x^{-j}$. Then $D$ is an interval. Moreover, if $D \neq[0,1]$, then $v_{t}\left(x^{j}\right)=v_{t}\left(x^{-j}\right)$ only for the endpoint of the interval $D$ that is strictly inside $[0,1]$.

Proof of Lemma 1. Suppose by way of contradiction that $D$ is not an interval for some $x^{j}, x^{-j}$. Note that we must have $x^{j} \neq x^{-j}$, else $D=[0,1]$. Then there exist $t<t^{\prime}<t^{\prime \prime}$ such that $t t^{\prime \prime} \in D$ but $t^{\prime} \notin D$. Continuity of utility in $t$ implies that there exists $t_{0}<t_{1}$ such that $v_{t_{0}}\left(x^{j}\right)=v_{t_{0}}\left(x^{-j}\right)$ and $v_{t_{1}}\left(x^{j}\right)=v_{t_{1}}\left(x^{-j}\right)$. Thus, the indifference curves of voters $t_{0}$ and $t_{1}$ intersect twice, which is a contradiction to (3). Hence, $D$ is an interval.

Moreover, if $D \neq[0,1]$, the preceding argument also implies that there cannot be two different types in $D$ who are indifferent between $x^{0}$ and $x^{1}$.

\section{Proof of Theorem 5. Proof of Part 1. Let}

$$
H(t, c)=\max _{a \in[0,1]} v_{t}\left(G_{0}(c, a), G_{1}(c, 1-a)\right)
$$

We first focus on what turns out to be the "interesting case" where no candidate can attract all of the voters, i.e., suppose that $H\left(0, c^{0}\right)>H\left(0, c^{1}\right)$ and $H\left(1, c^{0}\right)<H\left(1, c^{1}\right)$. Continuity of $H$ therefore implies 

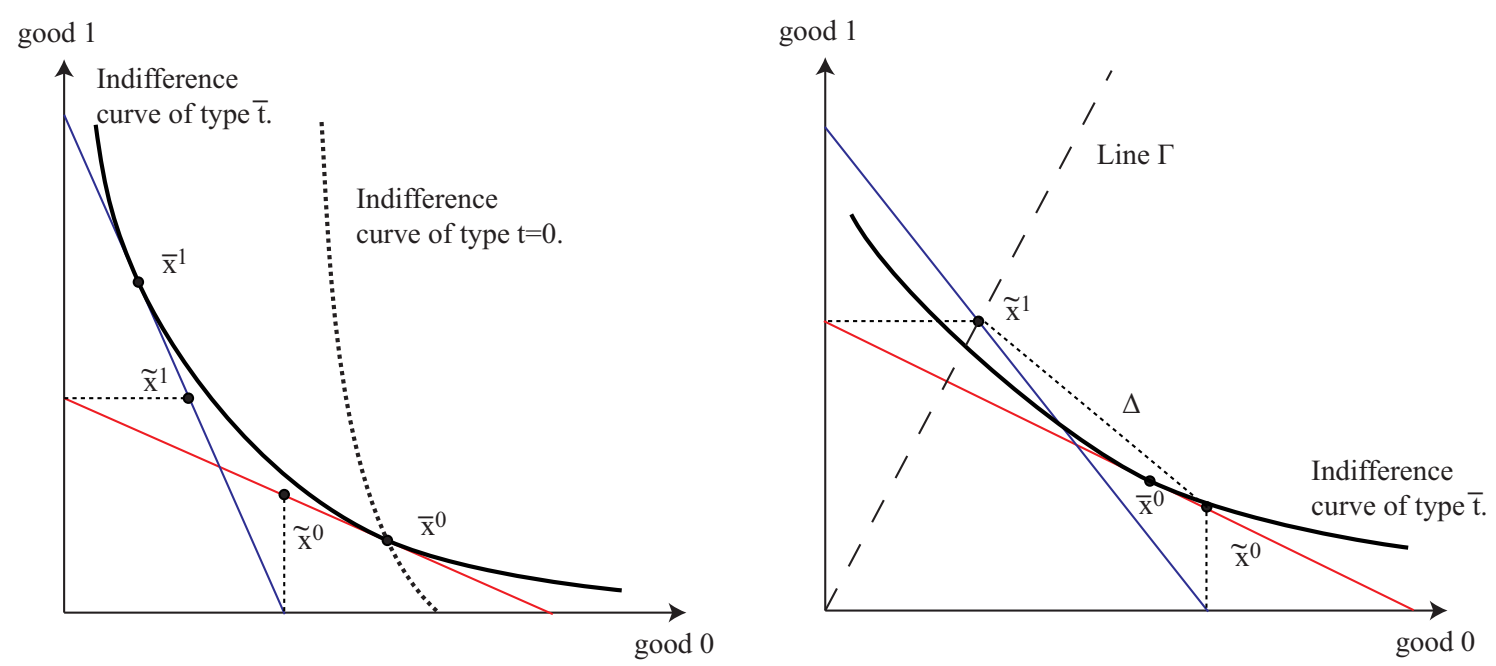

Figure 2: Illustration of the proof of claim 1 in Theorem 5

that there exists $\bar{t}$ such that $H\left(\bar{t}, c^{0}\right)=H\left(\bar{t}, c^{1}\right)$. Let $\bar{x}^{j}, i=0,1$, be the output of public goods and $\bar{a}^{j}$ be the optimal allocation of the input, i.e.,

$$
H\left(\bar{t}, c^{j}\right)=v_{\bar{t}}\left(x^{j}\right), \quad \bar{x}_{0}^{j}=G_{0}\left(c^{j}, \bar{a}^{j}\right), \quad x_{1}^{j}=G_{1}\left(c^{j}, \bar{a}^{j}\right)
$$

We now show that $\bar{a}^{j}, i=0,1$ is an equilibrium.

Suppose by way of contradiction, that Candidate 1 can improve by deviating to producing $\hat{x}^{1}$. Let $D=\left\{t \mid v_{t}\left(\hat{x}^{1}\right) \geq v_{t}\left(\bar{x}^{0}\right)\right\}$. If $1 \in D$, then $D$ is of the form $[\tilde{t}, 1]$, where $\tilde{t} \geq \bar{t}$. (Suppose otherwise; then, by Lemma $1, v_{\bar{t}}\left(\hat{x}^{1}\right)>v_{\bar{t}}\left(\bar{x}^{0}\right)$, which contradicts (25), i.e., that $x^{1}$ maximizes the utility of type $\bar{t}$ ). Thus, a deviation such that $1 \in D$ cannot increase Candidate 1's winning probability, as the set of types that vote for Candidate 1 is weakly smaller. Hence, the following claim completes the proof that Candidate 1 has no profitable deviation.

Claim 1. $1 \in$ D.

Figure 2 illustrates the intuition for the proof. The left panel of figure 2 illustrates the relationship between type $\bar{t}$ 's indifference curve and the equilibrium production levels $\bar{x}^{0}$ and $\bar{x}^{1}$ of both candidates. Clearly, the indifference curve must be tangent to the transformation frontier at both points. Suppose that $\bar{x}^{0}$ is to the right of $\tilde{x}^{0}$ as depicted in the left panel. It is then immediate that type 0 , whose dashed indifference curve is steeper than that of type $\bar{t}$, is strictly better off with $\bar{x}^{0}$ than with any public good bundle that Candidate 1 could offer. Hence type 0 would never vote for Candidate 1 . Since $D$ must either contain type 0 or type 1 by Lemma 1, this implies that $1 \in D$. Thus, in order to conclude the proof we must exclude the scenario depicted in the right panel of figure 2, where $\bar{x}^{0}$ is to the left of $\tilde{x}^{0}$. If the goods are sufficiently well substitutable, i.e., if (5) holds, then this limits the amount by which the MRS can change along the indifference curve (the limit on the change of the MRS can be related to a lower bound 
on the elasticity of substitution). In particular, suppose we move along the indifference curve of type $\bar{t}$, starting from $\bar{x}^{0}$ and ending at the intersection with the dashed line $\Gamma$. If the MRS at this intersection is still less than $\Delta$, then $\tilde{x}^{1}$ is above the indifference curve, as indicated in the right panel. This, however, means that voter $\bar{t}$ is not indifferent between the candidates. Candidate 1 could find a policy, such as $\tilde{x}^{1}$, that would make $\bar{t}$ strictly prefer him, which cannot be the case in equilibrium. We now proceed to the formal proof.

Proof of Claim 1. It is easy to check that the transformation frontier of a candidate with fixed position $c^{j}$ is given by

$$
\mathrm{TF}^{j}=\left\{\left(x_{0}^{j}, x_{1}^{j}\right) \in \mathbb{R}_{+}^{2} \mid x_{1}^{j}=B c^{j}-\frac{B c^{j}}{A\left(1-c^{j}\right)} x_{0}^{j}\right\} .
$$

Since $\bar{x}^{j}$ satisfies (25) it follows that the marginal rate of substitution of voter $\bar{t}$ must equal the slope of the transformation frontier:

$$
\operatorname{MRS}_{\bar{t}}\left(\bar{x}^{j}\right)=\frac{c^{j} B}{\left(1-c^{j}\right) A}
$$

The maximum amount of good 0 that Candidate 1 can produce is $\left(1-c^{1}\right) A$. Let $\tilde{x}^{0} \in \mathrm{TF}^{0}$ be

$$
\tilde{x}_{0}^{0}=\left(1-c^{1}\right) A, \quad \tilde{x}_{1}^{0}=c^{0} B\left[1-\frac{1-c^{1}}{1-c^{0}}\right] .
$$

Similarly, the maximum amount of good 1 that Candidate 0 can produce is $c^{0} B$. Let $\tilde{x}^{1} \in \mathrm{TF}^{1}$ be

$$
\tilde{x}_{0}^{1}=\left(1-c^{1}\right) A\left[1-\frac{c^{0}}{c^{1}}\right], \quad \tilde{x}_{1}^{1}=c^{0} B
$$

For $0 \in D$, we now show that $\bar{x}_{0}^{0}<\tilde{x}_{0}^{0}$ must hold. To see this, note that no point on the transformation frontier of Candidate 1 is strictly preferred to $\bar{x}^{0}$ by voter $\bar{t}$. The single crossing property (3) therefore implies that $v_{0}\left(x^{1}\right)<v_{0}\left(\bar{x}_{0}\right)$ for any point $x^{1}$ with $x_{0}^{1} \leq \bar{x}_{0}^{0}$. Thus, a necessary condition for the deviation to attract type 0 is that $\bar{x}_{0}^{0}<\tilde{x}_{0}^{0}$.

Let $L=\left\{\alpha x^{0}+(1-\alpha) x^{1} \mid 0<\alpha<1\right\}$ be the open line segment connecting $x^{0}$ and $x^{1}$, so that

$$
\Delta=-\frac{\tilde{x}_{1}^{1}-\tilde{x}_{1}^{0}}{\tilde{x}_{0}^{1}-\tilde{x}_{0}^{0}}
$$

is the (negative of the) slope of this line segment.

If $\operatorname{MRS}_{\bar{t}}\left(\tilde{x}^{1}\right)<\Delta$, then quasiconcavity of utility implies that $v_{\tilde{t}}\left(\tilde{x}^{1}\right)>v_{\bar{t}}(x)$ for all $x \in L$. Since $\tilde{x}_{0}^{1}<\bar{x}_{0}^{0}<\tilde{x}_{0}^{0}$ there exists $x \in L$ with $x \geq \bar{x}^{0}$. Thus monotonicity of preferences implies that $v_{t}\left(\bar{x}^{0}\right)<$ $v_{t}\left(\tilde{x}^{1}\right) \leq v_{\bar{t}}\left(\bar{x}^{1}\right)$, a contradiction. Thus,

$$
\operatorname{MRS}_{\bar{t}}\left(\tilde{x}^{1}\right) \geq \Delta
$$

In particular, let $\bar{I}=\left\{x \mid v_{\bar{t}}(x)=v_{\bar{t}}\left(\bar{x}^{0}\right)\right\}$ be type $\bar{t}^{\prime}$ s indifference curve through $\bar{x}^{0}$. If (31) were violated, then $\tilde{x}^{1}$ would be strictly above agent $\bar{t}^{\prime}$ s indifference curve $\bar{I}$. This would imply that $v_{\bar{t}}\left(\bar{x}^{1}\right)>v_{\bar{t}}\left(\bar{x}^{0}\right)$, a contradiction. 
Equations (28), (29) and (30) imply

$$
\frac{\Delta}{\operatorname{MRS}_{\bar{t}}\left(\bar{x}^{0}\right)}=\frac{c^{1}}{c^{0}}
$$

Further (28) and (29) yield

$$
\frac{\tilde{x}_{1}^{1} / \tilde{x}_{0}^{1}}{\tilde{x}_{1}^{0} / \tilde{x}_{0}^{0}}=\frac{\left(1-c^{0}\right) c^{1}}{\left(c^{1}-c^{0}\right)^{2}} .
$$

Let $\left(x_{1} / x_{0}\right)(M R S)$ be the good ratio $x_{1} / x_{0}$ on $\bar{I}$ as a function of the MRS. Since $\gamma$ is a lower bound for the elasticity of substitution we get

$$
\frac{\frac{\left(x_{1} / x_{0}\right)(M R S)}{d M R S}}{\left(x_{1} / x_{0}\right)(M R S)} \geq \frac{\gamma}{M R S} .
$$

Integrating both sides of (34) from $\operatorname{MRS}_{\bar{t}}\left(\bar{x}^{0}\right)$ to $\Delta$ and taking the exponential yields

$$
\left(\frac{\left(x_{1} / x_{0}\right)(\Delta)}{\left(x_{1} / x_{0}\right)\left(\operatorname{MRS}_{\bar{t}}\left(\bar{x}^{0}\right)\right.}\right)^{1 / \gamma} \geq \frac{\Delta}{\operatorname{MRS}_{\bar{t}}\left(\bar{x}^{0}\right)},
$$

Recall that $\bar{x}_{0}^{0}<\tilde{x}_{0}^{0}$. Hence, $\left(x_{1} / x_{0}\right)\left(\operatorname{MRS}_{\bar{t}}\left(\bar{x}^{0}\right)>\left(x_{1} / x_{0}\right)\left(\operatorname{MRS}_{\bar{t}}\left(\tilde{x}^{0}\right)\right.\right.$. This and (32) imply that the good ratio $x_{1} / x_{0}$ needed to get an MRS of $\Delta$ is strictly larger than $\tilde{x}_{1}^{1} / \tilde{x}_{0}^{1}$, and hence (35) implies

$$
\left(\frac{\tilde{x}_{1}^{1} / \tilde{x}_{0}^{1}}{\tilde{x}_{1}^{0} / \tilde{x}_{0}^{0}}\right)^{1 / \gamma}>\frac{\Delta}{\operatorname{MRS}_{\bar{t}}\left(\bar{x}^{0}\right)}
$$

Substituting (33) and (32) into (36) contradicts (5). Thus, $1 \in D$.

The proof that a deviation by Candidate 0 is not optimal it similar, except that we must replace (32) by

$$
\frac{\operatorname{MRS}_{\bar{t}}\left(\bar{x}^{1}\right)}{\Delta}=\frac{1-c^{0}}{1-c^{1}}
$$

As $\operatorname{MRS}_{\bar{t}}\left(\bar{x}^{0}\right)<\operatorname{MRS}_{\bar{t}}\left(\bar{x}^{1}\right)$, strict quasiconcavity implies that $x_{0}^{0}>x_{0}^{1}$ and $x_{1}^{1}>x_{1}^{0}$.

Finally note that the distribution of types does not affect the equilibrium. This proves the first statement.

The case where $H\left(0, c^{0}\right) \leq H\left(0, c^{1}\right)$ or $H\left(1, c^{0}\right) \geq H\left(1, c^{1}\right)$. Consider the first of the two scenarios as the other case is similar. Let $x^{1}$ be the consumption bundle provided by Candidate 1 that maximizes type 0's utility. Then $v_{0}\left(x^{1}\right) \geq v_{0}(x)$ for any $x \in \mathrm{TF}^{0}$. The single crossing property (3) immediately implies that $v_{t}\left(x^{1}\right)>v_{t}(x)$ for any $x \in \mathrm{TF}^{0}$ and for any $t>0$ and hence all citizens $t>0$ vote for Candidate 1 independently of Candidate 0 's strategy. Thus, $\left(x^{0}, x^{1}\right)$ is a Nash equilibrium, where $x^{0}$ is the consumption bundle that maximizes type 0 's utility on $\mathrm{TF}^{0}$. Clearly, $x_{0}^{0}>x_{0}^{1}$ and $x_{0}^{1}<x_{1}^{1}$.

Proof of Part 2. Let $\left(x^{0}, x^{1}\right)$ be the allocation of public goods offered by the candidates in a pure strategy equilibrium. By Lemma $1, D^{0}=\left\{t \mid v_{t}\left(x^{0}\right) \geq v_{t}\left(x^{1}\right)\right\}$ and $D^{1}=\left\{t \mid v_{t}\left(x^{1}\right) \geq v_{t}\left(x^{0}\right)\right\}$ are intervals. 
First, suppose that $D^{0}=D^{1}=[0,1]$. Clearly, each candidate's winning probability is 0.5 . Given the single crossing property (3) this implies $x^{0}=x^{1}$. Let $t_{m}(\omega)$ be the realization of the median voter type, and let $\hat{t}$ be the median of the distribution of $t(\omega)$. Since $c^{0} \neq c^{1}$ the transformation frontiers have different slopes. Thus, for at least one candidate $\operatorname{MRS}_{\hat{t}}\left(x^{j}\right)$ does not equal the slope of the candidate's transformation frontier. As a consequence, there exists a bundle of public goods $\hat{x}^{j}$ for Candidate $i$ such that $v_{\hat{t}}\left(\hat{x}^{j}\right)>v_{\hat{t}}\left(x^{j}\right)=v_{\hat{t}}\left(x^{-j}\right)$. Thus, Lemma 1 implies that $\hat{t}$ is in the interior of $\hat{D}=\left\{t \mid v_{t}\left(\hat{x}^{j}\right) \geq v_{t}\left(x^{-j}\right)\right\}$. Given that $\hat{D}$ contains the median of the median voters in its interior, and given that the distribution of types has strictly positive density, the winning probability for Candidate $j$ is strictly increased, a contradiction to the assumption that $x^{0}=x^{1}$ is a Nash equilibrium. Hence, $D^{0}$ and $D^{1}$ cannot both be equal to $[0,1]$.

Next, suppose that $D^{i}$ consists of only a single, point, i.e., $D^{i}=\{0\}$ or $D^{i}=\{1\}$. Continuity of preferences then implies that no citizen in $D^{i}$ has a strict preferences for Candidate $i$, and all of them will therefore abstain. Finally, since $t_{m}(\omega)=0$ or $t_{m}(\omega)=1$ with probability 0 , this implies that the other candidate will receive a strictly positive number of votes and therefore win $100 \%$ of all votes cast.

Thus, let $D^{j} \neq[0,1]$ for $i=0,1$. Further, by continuity of $v_{t}$ there exists exactly one type $t^{*}$ for which $v_{t^{*}}\left(x^{0}\right)=v_{t^{*}}\left(x^{1}\right)$. Suppose by way of contradiction that $H\left(t, c^{0}\right) \neq v_{t^{*}}\left(c^{0}\right)$, where $H$ is defined in (24). If $0 \in D^{0}$ then Lemma 1 implies $v_{0}\left(x^{0}\right)>v_{0}\left(x^{1}\right)$. Hence, there exists some $\tilde{x}^{0}$ such that $v_{0}\left(\tilde{x}^{0}\right)>v_{0}\left(x^{1}\right)$ and $v_{t^{*}}\left(\tilde{x}^{0}\right)>v_{t^{*}}\left(x^{0}\right)=v_{t^{*}}\left(x^{1}\right)$. Thus, $t^{*}$ is in the interior of $\tilde{D}^{0}=\left\{t \mid v_{t}\left(\tilde{x}^{0}\right) \geq v_{t}\left(x^{1}\right)\right\}$. Since $0 \in \tilde{D}^{0}$ and $\tilde{D}^{0}$ is an interval it follows that $\tilde{D}^{0}$ is a strict superset of $D^{0}$. Since the distribution of types has strictly positive density, this implies that the winning probability for Candidate 0 strictly increases, a contradiction. The proof where $1 \in D^{0}$ or agent 1 deviates is similar.

We now show that there exists exactly one $t$ that solves $H\left(t, c^{0}\right)=H\left(t, c^{1}\right)$. Suppose by way of contradiction that there exist $t<t^{\prime}$ such that $H\left(t, c^{0}\right)=H\left(t, c^{1}\right)$ and $H\left(t^{\prime}, c^{0}\right)=H\left(t^{\prime}, c^{1}\right)$. Then the indifference curves of type $t$ 's and that of type $t^{\prime}$ must be tangent both to $\mathrm{TF}^{0}$ and $\mathrm{TF}^{1}$. This, however, is only possible if the indifference curves intersect at at least two points, contradicting the single crossing property (3).

Given that a unique $t$ solves $H\left(t, c^{0}\right)=H\left(t, c^{1}\right)$, the Nash equilibrium is unique among all pure strategy Nash equilibria. Now suppose that there exists a mixed strategy equilibrium. Without loss of generality suppose that Candidate 1 mixes. By selecting $\bar{x}^{0}$ Candidate 0 can ensure that at least all types $t<\bar{t}$ vote for him. However, since Candidate 1 mixes, the candidate choose $\bar{x}^{1}$ with probability less than 1 . In such a case, there exists $\hat{t}>\bar{t}$ such that all citizens $t<\hat{t}$ vote for Candidate 0 , which strictly increases Candidate 0's winning probability as $t_{m}(\omega)$ has a strictly positive density. Thus, Candidate 0's winning probability in the mixed strategy equilibrium must be strictly larger than that in the pure strategy equilibrium. Similarly, it follows that Candidate 1's winning probability in the mixed strategy equilibrium must be at least as large as in the pure strategy equilibrium, a contradiction since the winning probabilities must add up to 1 . 
Finally, the Nash equilibrium is strict since preferences are strictly quasiconcave and therefore the solution to maximization problem (24) is unique. As a consequence, any deviation by Candidate 1 from $x^{j}$ to $\tilde{x}^{j}$ implies that $v_{\bar{t}}\left(x^{-j}\right)>v_{\bar{t}}\left(\tilde{x}^{j}\right)$. Hence, Candidate $i$ loses type $\bar{t}$. Since the distribution of types has a strictly positive density, this implies that Candidate $i$ 's winning probability strictly decreases.

Proof of Theorem 6. First, suppose that $\left(a^{*}, a^{*}\right)$ is competition efficient. Then this implies that

$$
\mu\left(\left\{\omega \mid Q\left(\omega, a^{*}, a^{*}, \hat{a}^{0}, a^{*}\right) \geq Q\left(\omega, \hat{a}^{0}, a^{*}, a^{*}, a^{*}\right)\right\}\right) \geq \mu\left(\left\{\omega \mid Q\left(\omega, \hat{a}^{0}, a^{*}, a^{*}, a^{*}\right) \geq Q\left(\omega, a^{*}, a^{*}, \hat{a}^{0}, a^{*}\right)\right\}\right),
$$

for all $\hat{a}^{0}$. Inserting the definition of $Q(\cdot)$ in (38) we get

$$
\begin{aligned}
& \mu\left(\left\{\omega \mid W^{0}\left(\omega, \hat{a}^{0}, a^{*}\right) \#\left\{\ell \mid a^{*} \geq_{\omega}^{\ell} \hat{a}^{0}\right\} \geq W^{0}\left(\omega, \hat{a}^{0}, a^{*}\right) \#\left\{\ell \mid \hat{a}^{0} \geq_{\omega}^{\ell} a^{*}\right\}\right)\right. \\
& \quad \geq \mu\left(\left\{\omega \mid W^{0}\left(\omega, \hat{a}^{0}, a^{*}\right) \#\left\{\ell \mid \hat{a}^{0} \geq_{\omega}^{\ell} a^{*}\right\} \geq W^{0}\left(\omega, \hat{a}^{0}, a^{*}\right) \#\left\{\ell \mid a^{*} \geq_{\omega}^{\ell} \hat{a}^{0}\right\}\right)\right.
\end{aligned}
$$

Thus, no policy $\hat{a}^{0}$ by Candidate 0 can win against $a^{*}$ with strictly positive probability. In particular, if $a^{0}$ wins against $a^{*}$ then $\#\left\{\ell \mid \hat{a}^{0} \geq_{\omega}^{\ell} a^{*}\right\}>\#\left\{\ell \mid a^{*} \geq_{\omega}^{\ell} \hat{a}^{0}\right\}$ and $W^{0}\left(\omega, \hat{a}^{0}, a^{*}\right)>0$. In order for (39) to be satisfied, this implies that both inequalities can only be satisfied on a set of measure zero.

It follows immediately that if we perturb the economy slightly there exist strategies that can win against $a^{*}$ with positive probability. In particular, let $\varepsilon>0$ be arbitrary and $\tilde{\Omega} \subset \Omega$ with $0<\mu(\tilde{\Omega})<\varepsilon$. Let $\hat{a}^{0} \neq a^{*}$. On $\tilde{\Omega}$ we redefine preferences such that all agents prefer $a^{0}$ to $a^{*}$, an hence $a^{0}$ would win for all $\omega \in \tilde{\Omega} .^{13}$

It remains to prove that if $\left(a^{*}, a^{*}\right)$ is not competition efficient, then the same is true in a neighborhood of the voting game. Since $\left(a^{*}, a^{*}\right)$ is not competition efficient there exists $\left(\hat{a}^{0}, \hat{a}^{1}\right)$ with

$$
\mu\left(\left\{\omega \mid Q\left(\omega, a^{*}, a^{*}, \hat{a}^{0}, \hat{a}^{1}\right) \geq Q\left(\omega, a^{*}, a^{*}, a^{0}, a^{1}\right)\right\}\right)<\mu\left(\left\{\omega \mid Q\left(\omega, \hat{a}^{0}, \hat{a}^{1}, a^{*}, a^{*}\right) \geq Q\left(\omega, a^{*}, a^{*}, \hat{a}^{0}, \hat{a}^{1}\right)\right\}\right) .
$$

Let $\delta=\min _{p \neq p^{\prime}} d\left(p, p^{\prime}\right)$, where $d$ is the metric on preferences $P_{r}$. Since $P_{r}$ is finite, $\delta>0$. Further, let $C$ be the difference between the right-hand and left-hand side of (40). Choose $\varepsilon$ with $0<\varepsilon<\min \{\delta, C / 2\}$. Denote the current random preference profile by $t$. If $d_{T^{L}}\left(t, t^{\prime}\right)<\varepsilon$ then this implies that $t$ and $t^{\prime}$ differ at most on a set $\tilde{\Omega}$ with $\tilde{\Omega}<\varepsilon$. This, however, implies that (40) remain valid if we replace the random preference profile $t$ by $t^{\prime}$, i.e., $\left(a^{*}, a^{*}\right)$ is not competition efficient in a neighborhood of $t$.

Proof of Theorem 7. Suppose by way of contradiction that $\left(c^{0}, a^{*}\right),\left(c^{1}, a^{*}\right)$ is not a Nash equilibrium. Without loss of generality we can therefore assume that there exists that a deviation $a^{0}$ that weakly increases Candidate 0's winning probability.

We first show that Candidate 0 must win in states $\omega \in \psi^{-1}(0)$ when using strategy $\left(c^{0}, a^{*}\right)$ (note that $\psi^{-1}(0) \neq \emptyset$ by assumption 2 . In particular, suppose by way of contradict that Candidate 0 loses

\footnotetext{
${ }^{13}$ Note, however, that $\left(a^{0}, a^{*}\right)$ will not be an equilibrium for sufficiently small $\varepsilon$ if $a^{0}$ loses against $a^{*}$ outside $\tilde{\Omega}$.
} 
in these states. Then Candidate 0 must lose also in all states $\omega^{\prime} \in \psi^{-1}((-\infty, 0))$. Again, this follows from strict monotonicity of $g$. That is, suppose that $g\left(f\left(c^{0}, \omega\right), h_{\ell}\left(a^{0}\right)\right) \leq g\left(f\left(c^{1}, \omega\right), h_{\ell}\left(a^{*}\right)\right)$. Since, $f\left(c^{0}, \omega\right)=f\left(c^{1}, \omega\right)$, it follows that $\left.h_{\ell}\left(a^{0}\right)\right) \leq h_{\ell}\left(a^{*}\right)$. Thus, $g\left(x, h_{\ell}\left(a^{0}\right)\right) \leq g\left(x, h_{\ell}\left(a^{*}\right)\right)$ for any $x \in \mathbb{R}$, and as a consequence, $g\left(x, h_{\ell}\left(a^{0}\right)\right)<g\left(x^{\prime}, h_{\ell}\left(a^{*}\right)\right)$ when $x>x^{\prime}$. Thus, $g\left(f\left(c^{0}, \omega^{\prime}\right), h_{\ell}\left(a^{0}\right)\right)<g\left(f\left(c^{1}, \omega^{\prime}\right), h_{\ell}\left(a^{*}\right)\right)$ for all $\omega^{\prime} \in \psi^{-1}((-\infty, 0))$. However, this means that Candidate 0 's expected winning probability does not increase when switching from $a^{*}$ to $a^{0}$, a contradiction.

If Candidate 0 wins in states $\omega \in \psi^{-1}(0)$ then this implies that $\#\left\{\ell \mid h_{\ell}\left(a^{0}\right) \geq h_{\ell}\left(a^{*}\right)\right\}>\#\left\{\ell \mid h_{\ell}\left(a^{*}\right) \geq\right.$ $\left.h_{\ell}\left(a^{0}\right)\right\}$, a contradiction to condition 3 of the Theorem. Thus, $\left(c^{0}, a^{*}\right),\left(c^{1}, a^{*}\right)$ is a Nash equilibrium.

To show that the equilibrium is competition efficient consider an arbitrary collection of strategies $\left(c^{0}, a^{0}\right),\left(c^{1}, a^{1}\right)$. Let $\omega \in \Omega$. Then condition 3 implies that a majority of voters would prefer $a^{*}$ to either $a^{0}$ and $a^{1}$. Thus, $\left(c^{0}, a^{*}\right),\left(c^{1}, a^{*}\right)$ is competition-efficient. 


\section{References}

Adams, J. and S. Merrill (2003). Voter turnout and candidate strategies in american elections. Journal of Politics 65, 161-189.

Ahn, D. and S. Oliveros (2008). Combinatorial voting. UC Berkeley.

Ansolabehere, S. and J. M. Snyder (2000). Valence politics and equilibrium in spatial election models. Public Choice 103, 327-336.

Bernhardt, D., J. Duggan, and F. Squintani (2006). Private polling in elections and voter welfare. mimeo, University of Illinois.

Besley, T. and S. Coate (1997). An economic model of representative democracy. Quarterly Journal of Economics 112, 85-114.

Callander, S. (2005). Electoral competition in heterogeneous districts. Journal of Political Economy 113, 1116-1145.

Callander, S. (2008). Political motivations. Review of Economic Studies 75, 671-697.

Calvert, R. L. (1985). Robustness of the multidimensional voting model: Candidate motivations, uncertainty, and convergence. American Journal of Political Science 29, 69-95.

Castanheira, M. (2003). Why vote for losers? Journal of the European Economic Association 1(5), $1207-1238$.

Coughlin, P. (1992). Probabilistic Voting Theory. Cambridge, Cambridge University Press.

Dal Bo, E., P. Dal Bo, and J. Snyder (2006). Political dynasties. forthcoming, Review of Economic Studies.

Downs, A. (1957). An economic theory of democracy. Harper \& Row.

Egan, P. J. (2008). Issue ownership and representation: A theory of legislative responsiveness to constituency opinion. New York University.

Erikson, R. and D. Romero (1990). Candidate equilibrium and the behavioral model of the vote. American Political Science Review 84, 1103-1126.

Grofman, B. (2004). Downs and two-party convergence. Annual Review of Political Science 7, 25-46.

Gul, F. and W. Pesendorfer (2009). Partisan politics and aggregation failure with ignorant voters. Journal of Economic Theory 144, 146-174.

Krasa, S. and M. K. Polborn (2007). The binary policy model. University of Illinois.

Lindbeck, A. and J. Weibull (1987). Balanced-budget redistribution as the outcome of political competition. Public Choice 52, 273-297.

Lindbeck, A. and J. Weibull (1993). A model of political equilibrium in a representative democracy. Journal of Public Economics 51, 195-209.

Martinelli, C. (2001). Elections with privately informed parties and voters. Public Choice 108(1), $147-167$. 
Myerson, R. (1993). Review of: Advances in the spatial theory of voting. Journal of Economic Literature 31, 237-240.

Osborne, M. (1995). Spatial models of political competition under plurality rule: A survey of some explanations of the number of candidates and the positions they take. Canadian Journal of Economics 27, 261-301.

Osborne, M. and A. Slivinski (1996). A model of political competition with citizen candidates. Quarterly Journal of Economics 111, 65-96.

Palfrey, T. R. (1984). Spatial equilibrium with entry. Review of Economic Studies 51, 139-156.

Petrocik, J. R. (1996). Issue ownership in presidential elections, with a 1980 case study. American Journal of Political Science 40(3), 825-850.

Petrocik, J. R., W. L. Benoit, and G. Hansen (2003). Issue ownership and presidential campaigning, 1952-2000. Political Science Quarterly 118(4), 599-626.

Roemer, J. E. (1994). A theory of policy differentiation in single issue electoral politics. Social Choice and Welfare 11(4), 355-380.

Shepsle, K. A. (1979). Institutional arrangements and equilibrium in multidimensional voting models. American Journal of Political Science 23(1), 27-59.

Shepsle, K. A. and B. R. Weingast (1981). Structure-induced equilibrium and legislative choice. Public Choice 37(3), 503 - 519.

Tullock, G. (1981). Why so much stability? Public Choice 37, 189-202.

Wittman, D. (1983). Candidate motivation: A synthesis of alternative theories. American Political Science Review 77, 142-157. 


\section{CESifo Working Paper Series}

for full list see www.cesifo-group.org/wp

(address: Poschingerstr. 5, 81679 Munich, Germany, office@cesifo.de)

2497 Scott Alan Carson, Nineteenth Century Black and White US Statures: The Primary Sources of Vitamin D and their Relationship with Height, December 2008

2498 Thomas Crossley and Mario Jametti, Pension Benefit Insurance and Pension Plan Portfolio Choice, December 2008

2499 Sebastian Hauptmeier, Ferdinand Mittermaier and Johannes Rincke, Fiscal Competition over Taxes and Public Inputs: Theory and Evidence, December 2008

2500 Dirk Niepelt, Debt Maturity without Commitment, December 2008

2501 Andrew Clark, Andreas Knabe and Steffen Rätzel, Boon or Bane? Others' Unemployment, Well-being and Job Insecurity, December 2008

2502 Lukas Menkhoff, Rafael R. Rebitzky and Michael Schröder, Heterogeneity in Exchange Rate Expectations: Evidence on the Chartist-Fundamentalist Approach, December 2008

2503 Salvador Barrios, Harry Huizinga, Luc Laeven and Gaëtan Nicodème, International Taxation and Multinational Firm Location Decisions, December 2008

2504 Andreas Irmen, Cross-Country Income Differences and Technology Diffusion in a Competitive World, December 2008

2505 Wenan Fei, Claude Fluet and Harris Schlesinger, Uncertain Bequest Needs and LongTerm Insurance Contracts, December 2008

2506 Wido Geis, Silke Uebelmesser and Martin Werding, How do Migrants Choose their Destination Country? An Analysis of Institutional Determinants, December 2008

2507 Hiroyuki Kasahara and Katsumi Shimotsu, Sequential Estimation of Structural Models with a Fixed Point Constraint, December 2008

2508 Barbara Hofmann, Work Incentives? Ex Post Effects of Unemployment Insurance Sanctions - Evidence from West Germany, December 2008

2509 Louis Hotte and Stanley L. Winer, The Demands for Environmental Regulation and for Trade in the Presence of Private Mitigation, December 2008

2510 Konstantinos Angelopoulos, Jim Malley and Apostolis Philippopoulos, Welfare Implications of Public Education Spending Rules, December 2008

2511 Robert Orlowski and Regina T. Riphahn, The East German Wage Structure after Transition, December 2008 
2512 Michel Beine, Frédéric Docquier and Maurice Schiff, International Migration, Transfers of Norms and Home Country Fertility, December 2008

2513 Dirk Schindler and Benjamin Weigert, Educational and Wage Risk: Social Insurance vs. Quality of Education, December 2008

2514 Bernd Hayo and Stefan Voigt, The Relevance of Judicial Procedure for Economic Growth, December 2008

2515 Bruno S. Frey and Susanne Neckermann, Awards in Economics - Towards a New Field of Inquiry, January 2009

2516 Gregory Gilpin and Michael Kaganovich, The Quantity and Quality of Teachers: A Dynamic Trade-off, January 2009

2517 Sascha O. Becker, Peter H. Egger and Valeria Merlo, How Low Business Tax Rates Attract Multinational Headquarters: Municipality-Level Evidence from Germany, January 2009

2518 Geir H. Bjønnes, Steinar Holden, Dagfinn Rime and Haakon O.Aa. Solheim, ,Large’ vs. ,Small' Players: A Closer Look at the Dynamics of Speculative Attacks, January 2009

2519 Jesus Crespo Cuaresma, Gernot Doppelhofer and Martin Feldkircher, The Determinants of Economic Growth in European Regions, January 2009

2520 Salvador Valdés-Prieto, The 2008 Chilean Reform to First-Pillar Pensions, January 2009

2521 Geir B. Asheim and Tapan Mitra, Sustainability and Discounted Utilitarianism in Models of Economic Growth, January 2009

2522 Etienne Farvaque and Gaël Lagadec, Electoral Control when Policies are for Sale, January 2009

2523 Nicholas Barr and Peter Diamond, Reforming Pensions, January 2009

2524 Eric A. Hanushek and Ludger Woessmann, Do Better Schools Lead to More Growth? Cognitive Skills, Economic Outcomes, and Causation, January 2009

2525 Richard Arnott and Eren Inci, The Stability of Downtown Parking and Traffic Congestion, January 2009

2526 John Whalley, Jun Yu and Shunming Zhang, Trade Retaliation in a Monetary-Trade Model, January 2009

2527 Mathias Hoffmann and Thomas Nitschka, Securitization of Mortgage Debt, Asset Prices and International Risk Sharing, January 2009

2528 Steven Brakman and Harry Garretsen, Trade and Geography: Paul Krugman and the 2008 Nobel Prize in Economics, January 2009 
2529 Bas Jacobs, Dirk Schindler and Hongyan Yang, Optimal Taxation of Risky Human Capital, January 2009

2530 Annette Alstadsæter and Erik Fjærli, Neutral Taxation of Shareholder Income? Corporate Responses to an Announced Dividend Tax, January 2009

2531 Bruno S. Frey and Susanne Neckermann, Academics Appreciate Awards - A New Aspect of Incentives in Research, January 2009

2532 Nannette Lindenberg and Frank Westermann, Common Trends and Common Cycles among Interest Rates of the G7-Countries, January 2009

2533 Erkki Koskela and Jan König, The Role of Profit Sharing in a Dual Labour Market with Flexible Outsourcing, January 2009

2534 Tomasz Michalak, Jacob Engwerda and Joseph Plasmans, Strategic Interactions between Fiscal and Monetary Authorities in a Multi-Country New-Keynesian Model of a Monetary Union, January 2009

2535 Michael Overesch and Johannes Rincke, What Drives Corporate Tax Rates Down? A Reassessment of Globalization, Tax Competition, and Dynamic Adjustment to Shocks, February 2009

2536 Xenia Matschke and Anja Schöttner, Antidumping as Strategic Trade Policy Under Asymmetric Information, February 2009

2537 John Whalley, Weimin Zhou and Xiaopeng An, Chinese Experience with Global 3G Standard-Setting, February 2009

2538 Claus Thustrup Kreiner and Nicolaj Verdelin, Optimal Provision of Public Goods: A Synthesis, February 2009

2539 Jerome L. Stein, Application of Stochastic Optimal Control to Financial Market Debt Crises, February 2009

2540 Lars P. Feld and Jost H. Heckemeyer, FDI and Taxation: A Meta-Study, February 2009

2541 Philipp C. Bauer and Regina T. Riphahn, Age at School Entry and Intergenerational Educational Mobility, February 2009

2542 Thomas Eichner and Rüdiger Pethig, Carbon Leakage, the Green Paradox and Perfect Future Markets, February 2009

2543 M. Hashem Pesaran, Andreas Pick and Allan Timmermann, Variable Selection and Inference for Multi-period Forecasting Problems, February 2009

2544 Mathias Hoffmann and Iryna Shcherbakova, Consumption Risk Sharing over the Business Cycle: the Role of Small Firms' Access to Credit Markets, February 2009 
2545 John Beirne, Guglielmo Maria Caporale, Marianne Schulze-Ghattas and Nicola Spagnolo, Volatility Spillovers and Contagion from Mature to Emerging Stock Markets, February 2009

2546 Ali Bayar and Bram Smeets, Economic and Political Determinants of Budget Deficits in the European Union: A Dynamic Random Coefficient Approach, February 2009

2547 Jan K. Brueckner and Anming Zhang, Airline Emission Charges: Effects on Airfares, Service Quality, and Aircraft Design, February 2009

2548 Dolores Messer and Stefan C. Wolter, Money Matters - Evidence from a Large-Scale Randomized Field Experiment with Vouchers for Adult Training, February 2009

2549 Johannes Rincke and Christian Traxler, Deterrence through Word of Mouth, February 2009

2550 Gabriella Legrenzi, Asymmetric and Non-Linear Adjustments in Local Fiscal Policy, February 2009

2551 Bruno S. Frey, David A. Savage and Benno Torgler, Surviving the Titanic Disaster: Economic, Natural and Social Determinants, February 2009

2552 Per Engström, Patrik Hesselius and Bertil Holmlund, Vacancy Referrals, Job Search, and the Duration of Unemployment: A Randomized Experiment, February 2009

2553 Giorgio Bellettini, Carlotta Berti Ceroni and Giovanni Prarolo, Political Persistence, Connections and Economic Growth, February 2009

2554 Steinar Holden and Fredrik Wulfsberg, Wage Rigidity, Institutions, and Inflation, February 2009

2555 Alexander Haupt and Tim Krieger, The Role of Mobility in Tax and Subsidy Competition, February 2009

2556 Harald Badinger and Peter Egger, Estimation of Higher-Order Spatial Autoregressive Panel Data Error Component Models, February 2009

2557 Christian Keuschnigg, Corporate Taxation and the Welfare State, February 2009

2558 Marcel Gérard, Hubert Jayet and Sonia Paty, Tax Interactions among Belgian Municipalities: Does Language Matter?, February 2009

2559 António Afonso and Christophe Rault, Budgetary and External Imbalances Relationship: A Panel Data Diagnostic, February 2009

2560 Stefan Krasa and Mattias Polborn, Political Competition between Differentiated Candidates, February 2009 